\title{
In vitro synergistic potentials of novel antibacterial combination therapies against Salmonella Typhimurium and Escherichia coli
}

\section{Md. Akil Hossain}

Animal and Plant Quarantine Agency https://orcid.org/0000-0001-7131-4814

Hae-Chul Park

Animal and Plant Quarantine Agency

Kwang-jick Lee

Animal and Plant Quarantine Agency

Sung-Won Park

Animal and Plant Quarantine Agency

Seung-Chun Park

Kyungpook National University

JeongWoo Kang ( $\nabla$ hijach@korea.kr)

\section{Research article}

Keywords: Combination therapy, critically important antibiotics, Phenolic compounds, gallic acid, hamamelitannin, biofilm.

Posted Date: November 18th, 2019

DOl: https://doi.org/10.21203/rs.2.9511/v3

License: (c) (i) This work is licensed under a Creative Commons Attribution 4.0 International License.

Read Full License

Version of Record: A version of this preprint was published at BMC Microbiology on May 14th, 2020. See the published version at https://doi.org/10.1186/s12866-020-01810-x. 


\section{Abstract}

Background: The antibiotics generally used in farm animals are rapidly losing their effectiveness all over the world as bacteria develop antibiotic resistance. New strategies are needed to block the development

of resistance and to prolong the life of traditional antibiotics. This study aimed to increase the efficacy of existing antibiotics by combining them with the opportunistic phenolic compounds gallic acid (GA), epicatechin, epicatechin gallate, epigallocatechin and hamamelitannin. Fractional inhibitory concentration index ( $\mathrm{FICl}$ ) of phenolic compound-antibiotic combinations against Salmonella enterica serovar Typhimurium (S. Typhimurium) and Escherichia coli (E. coli) were determined. Based on the FICI and clinical importance, 3 combinations were selected to evaluate their effects on the virulence factors of these bacteria. The in vitro cytotoxicity of GA and hamamelitannin in Rattus norvegicus (IEC-6) cell lines were evaluated. Results: Minimum inhibitory concentrations (MICs) of epigallocatechin, GA and hamamelitannin found against different strains were (512-1024), (256-1024) and (512-2048) $\mu \mathrm{g} / \mathrm{mL}$, respectively. Synergistic effects were obtained from combinations of thiamphenicol-GA (FICl: 0.28), erythromycin-hamamelitannin (FICl: 0.38) and thiamphenicol-hamamelitannin (FICl: 0.50) against E. coli, and erythromycin-epicatechin gallate (FICl: 0.50 ) against $\mathrm{S}$. Typhimurium. Moreover, additive effects were obtained from 33 combinations against S. Typhimurium (FICl: 0.502 0.750) and E. coli (FICl: $0.502 \sim 0.625)$. The time-kill assays and ultrastructural morphology showed that GA-ceftiofur, and hamamelitannin-erythromycin and GA-ampicillin combinations more efficiently inhibited the growth of S. Typhimurium and E. coli, respectively, compared to individual antibiotics. Biofilm viability and swimming and swarming motilities of S. Typhimurium in presence of GA-ceftiofur, and $\mathrm{E}$. coli in presence of hamamelitannin-erythromycin and GA-ampicillin combinations were more competently inhibited than individual antimicrobials. The inhibitory concentrations $50 \%$ (IC50) of GA and hamamelitannin in IEC-6 cells were $564.55 \mu \mathrm{M}$ and $988.54 \mu \mathrm{M}$, respectively. Conclusions: This study suggest that GA-ceftiofur combination can be potential medication to treat S. Typhimurium-associated diarrhea and prevent $\mathrm{S}$. Typhimurium-associated blood-stream infections (e.g.: fever) in farm animals. Hamamelitanninerythromycin and GA-ampicillin combinations can be effective in restricting E. coli contamination in farm animals, and ultimately its transmission from animal to human. Further study to confirm these effects and safety profiles in in vivo system should be undertaken for establishing these combinations as medications.

\section{Background}

Livestock (farm animals) are one of the most important and rapidly expanding commercial agricultural sectors worldwide. Infectious diseases cause direct losses to this sector through increased mortality and reduced livestock productivity, as well as indirect losses associated with cost of control, loss of trade, decreased market values, and food insecurity [1]. Multidrug-resistant (MDR) bacteria are one of several vital aetiologic agents contributing to the emergence of infections [2]. The rapid emergence of resistant bacteria is occurring worldwide, endangering the efficacy of antibiotics [3-8]. The antibiotic resistance crisis has been attributed to the overuse and misuse of these medications, as well as a lack of new drug 
development by the pharmaceutical industry due to reduced economic incentives and challenging regulatory requirements $[4-7,9-16]$. A number of bacteria are classified for presenting urgent, serious, and concerning threats, many of which are already evident for placing substantial clinical and financial burden to the health care system $[3,17]$.

The frequency of resistance is observed equally among Gram-negative and Gram-positive organisms, although Gram-negative bacteria are more prone to develop the MDR phenotype [2]. Together with other bacterial species, Escherichia coli and Salmonella enterica serovar Typhimurium are severely antibioticresistant and were recently enlisted and designated as priority class bacterial pathogens in urgent need of effective antibiotics [18]. The gravity of the situation is highlighted by the fact that clinical isolates of these species have up to 1000 -fold higher $50 \%$ growth inhibition concentrations $\left(\mathrm{GIC}_{50}\right)$ for a range of antibiotics with different mechanisms of action relative to the sensitive/resistant breakpoints recommended by the Clinical and Laboratory Standard Institute (CLSI). These trends show the urgent need for the development of new antimicrobials that can treat or potentiate current antibiotics against MDR bacteria [19]. The scientific community is continuously searching for new classes of disinfection systems that could act efficiently against these pathogens [20]. Certain naturally occurring phenolic compounds have antioxidant, anticarcinogenic, and antimicrobial activities [21, 22].

The phenolic compound (methyl gallate and pyrogallol)-containing Nymphaea tetragona $50 \%$ methanol extract (NTME) was found to have quorum sensing and virulence factor inhibitory effects [23]. The synergistic antibacterial and quorum sensing (QS) inhibition effects of the phenolic compoundcontaining NTME were also evident in our earlier study [24]. The phenolic compound gallic acid demonstrated the potential to inhibit $S$. mutans biofilms [25]. Recently, we also reported that methyl gallate, a gallic acid (GA) derivative, can efficiently interfere with the QS regulatory pathways of $P$. aeruginosa and inhibit the adhesion, invasion and intracellular survival of $S$. Typhimurium [26, 27]. These properties of bacteria are known to have a significant role in increasing pathogenicity and antimicrobial resistance [28].

GA derivatives contain a large number of hydroxyls, which can form protonic and ionic bonds and combine with many biological proteins, such as enzymes, carriers, ion channels and receptors, deactivating them and consequently exhibiting bacterial inhibition. Additionally, many phenols can nonspecifically affect molecular targets of microorganism [29]. These observations initiate the speculation that GA derivatives may also potentiate the efficacy of existing antibiotics. Thus, we intended in this study to evaluate the antibacterial potentials of GA and its 4 derivatives individually; and in combination with 8 commercially available antibiotics against $S$. Typhimurium and $E$. coli. Additionally, the effects of those combination antibacterials against selected virulence factors, including biofilm formation and motility were determined. Finally, the viability of in IEC- 6 cells in presence of GA and hamamelitannin alone and in combination with phenolic compounds were investigated.

\section{Materials And Methods}




\section{Chemicals, reagents and bacterial strains}

Luria-bertani (LB), mueller hinton agar (MHA), mueller hinton broth (MHB); cation-adjusted (CA)-MHB, nutrient broth (NB), trypticase soy broth (TSB), and agar were purchased from Becton Dickinson and Company (Becton Drive, NJ, United States), and sodium chloride and glucose were obtained from Scharlab (Barcelona, Spain). All these microbiological media were prepared before use by following manufacturer's instructions. Quality control strains of E. coli (ATCC 25922) and S. Typhimurium (ATCC 14028), and clinical strains of S. Typhimurium (V08-S-HA-06-170, V15-S-HA-02-210, SAL 109, SAL 202 and SAL 224) were used in this study. These clinical strains were obtained from farms of different regions in the Republic of Korea. Clinical isolated strains V08-S-HA-06-170 and SAL 109 were from feces of cattle, V15-S-HA-02-210 and SAL 202 were from feces of chicken and SAL 224 was from carcass of chicken. Based on the antibiotic sensitivity patterns, the clinical strains V08-S-HA-06-170 and V15-S-HA02-210 were characterized as intermediate resistant, and SAL 109, SAL 202 and SAL 224 were identified as resistant. All the strains were cultivated in MHB for $20 \mathrm{~h}$ in a rotating incubator at $200 \mathrm{rpm}$ and $37^{\circ} \mathrm{C}$. Antibiotics used in this study include amoxicillin, ampicillin, cefotaxime, ceftiofur, erythromycin, florfenicol, marbofloxacin, norfloxacin, penicillin $\mathrm{G}$ and thiamphenicol. GA, epicatechin, epicatechin gallate, epigallocatechin and hamamelitannin were utilized as antibacterial agent in this study. All the chemicals, reagents and media were from Sigma-Aldrich (St. Louis, MO, United States) unless otherwise mentioned. Stock solutions of epicatechin, epicatechin gallate and epigallocatechin were prepared by dissolving in water. Slight heat and sonication was applied to dissolve epicatechin gallate in water. Alcohol was used as co-solvent to dissolve GA and hamamelitannin in preparing stock solutions. All these stock solutions were further diluted to respective media (e.g., MHB, TSB, etc.) before using in experiment. Solvent controls were used where it was required. Respective growth media (e.g., MHB, TSB, etc.) were used as control medium in the combination experiment, unless mentioned otherwise.

\section{Minimum inhibition concentrations of antibacterial agents}

MICs of above mentioned commercial antibiotics and opportunistic antibacterial agents were determined by the standard broth microdilution method according to the CLSI guidelines [30] in CA-MHB using an inoculum concentration of $\sim 5 \times 10^{5} \mathrm{CFU} / \mathrm{mL}$. Different antibacterial solutions were serially diluted in $96-$ well plates in $100 \mu \mathrm{L}$ volumes. The cultures of different bacterial strains were diluted to adjust 0.5 McFarland units and, again diluted 100-times. Hundred microliters of these diluted bacterial suspensions were dispensed to all the wells of 96 -well plates which contain $100 \mu \mathrm{L}$ of antibacterial solution. After incubation at $35^{\circ} \mathrm{C}$ overnight, the turbidity in each well was checked. The lowest concentrations of the antibacterial that completely inhibited any increase in turbidity were considered as the MICs.

\section{Fractional inhibition concentration index of antibacterial agents}


A slightly modified version of the previously described checkerboard microdilution method was utilized to determine the combination interactions of the commercial antibiotics and phenolic compounds [31]. One antibacterial agent was vertically diluted and the other antibacterial was horizontally diluted in 96-well plates to achieve a matrix of different combinations of the 2 antibacterials. Similar dilutions of individual drugs and the drug-free medium control were included in each test plate. Bacterial cultures in early log phase were diluted and $100 \mu \mathrm{L}$ of the diluted bacterial suspension was added to each well of the 96 -well plates, where the final inoculum concentration after transferring to each well would be $\sim 5 \times 10^{5} \mathrm{CFU} / \mathrm{mL}$. Plated bacteria were incubated at $35^{\circ} \mathrm{C}$ for 16 to $20 \mathrm{~h}$. The fractional inhibitory concentration (FIC) and the FIC index (FICl) were calculated from the MICs of the drugs alone and in combination. The FIC is the MIC of a drug in presence of another drug divided by the MIC of the individual drug, and the $\mathrm{FICl}$ is the sum of the FICs of the individual drugs. An FICl of $\leq 0.5$ is regarded as synergistic, $0.5<\mathrm{FICl} \leq 1$ is considered additive, $1<\mathrm{FICl} \leq 2$ is considered indifferent, and an $\mathrm{FICl}>2$ is considered antagonistic effects [32].

\section{Effect of antibacterial combinations on bacterial inhibition rates}

The time-dependent inhibition effects of GA-ceftiofur against $S$. Typhimurium and hamamelitanninerythromycin and GA-ampicillin against $E$. coli were evaluated according to a previously reported method [24]. Drug compounds alone and in combination were supplemented in $10 \mathrm{~mL}$ MHB broth in $15 \mathrm{~mL}$ falcon tubes. Bacterial cultures in early log phase were diluted and then resuspended in the drug-supplemented broth to a final inoculum concentration of $5 \times 10^{6} \mathrm{CFU} / \mathrm{mL}$. A tube containing $5 \times 10^{6} \mathrm{CFU} / \mathrm{mL}$ of bacteria in $10 \mathrm{~mL}$ MHB without any drug was used as a control. The samples were incubated at $37^{\circ} \mathrm{C}$ at $200 \mathrm{rpm}$ in a shaking incubator. At different time points $(0,1,2,3,4,6,8,12$, and $24 \mathrm{~h}) 100 \mu \mathrm{L}$ of the cultures were collected from all tubes and serially diluted 10 -fold in agar saline. Aliquots of the 10 -fold dilutions $(20 \mu \mathrm{L})$ were spread on Mueller Hinton agar (MHA) plates and incubated overnight at $37^{\circ} \mathrm{C}$. The CFUs of the cultures were determined by counting the number of colonies from each dilution. The mean $\log ^{10}$ $\mathrm{CFU} / \mathrm{mL}$ for each compound was plotted against different times.

\section{Effect of antibacterial combinations on bacterial cell morphology}

The effects of the GA-ceftiofur combination on the morphology of $S$. Typhimurium and the hamamelitannin-erythromycin and GA-ampicillin combinations on the morphology of $E$. coli cells were evaluated. Drug compounds alone or in combination were supplemented into $10 \mathrm{~mL}$ of MHB broth in 15 $\mathrm{mL}$ falcon tubes. Bacterial cultures in early log phase were diluted and then resuspended in the drugsupplemented broth to a final inoculum concentration of $5 \times 10^{6} \mathrm{CFU} / \mathrm{mL}$. A tube containing $5 \times 10^{6}$ $\mathrm{CFU} / \mathrm{mL}$ of bacteria in $10 \mathrm{~mL}$ MHB without any drug was used as a control. The bacteria in tubes were incubated overnight at $37^{\circ} \mathrm{C}$ and $200 \mathrm{rpm}$ in a shaking incubator. Then, the cells were harvested, washed, and dehydrated according to a previously reported protocol [33]. The ultrastructural morphology of 
treated $S$. Typhimurium and $E$. coli cells was studied using a scanning electronic microscope (SEM; models S-4300 and EDX-350; Hitachi, Japan).

\section{Effect of antibacterial combinations on biofilm growth and viability}

The inhibitory effect of combination antibacterials on biofilm formation was determined using slightly modified version of a previously reported spectrophotometric method [34,35]. Briefly, test compounds were supplemented into TSB in three separate wells of a 96-well microplate for each concentration. The final concentrations of the test compounds alone or in combination (GA-ceftiofur, GA-ampicillin and hamamelitannin-erythromycin) were $1 / 4 \mathrm{MIC}, 1 / 2 \mathrm{MIC}$ and $1 \mathrm{MIC}$ after bacterial inoculation. Cultures of $S$. Typhimurium and $E$. coli were incubated for $18 \mathrm{~h}$ in a rotating incubator at $200 \mathrm{rpm}$ and $37^{\circ} \mathrm{C}$. The bacterial cultures were diluted in TSB, and then $100 \mu \mathrm{L}$ of the diluted cultures were added to the designated wells to a final cell density of $1 \times 10^{6} \mathrm{CFU} / \mathrm{mL}$ after inoculation. The optical densities of the bacteria in the wells of a 96-well plate were measured at $600 \mathrm{~nm}$ instantly after inoculating bacteria. The bacteria in the 96 -well plate with drugs were incubated for $24 \mathrm{~h}$ at $37^{\circ} \mathrm{C}$, and after incubation, the optical densities were again measured to determine the growth of planktonic cells. Then the supernatants from the wells of a 96-well plate were discarded carefully without affecting the biofilms which are attached on the well-surfaces. The adherent media and drug components were removed by washing the wells threetimes with sterile phosphate buffer saline (PBS, pH 7.2). Then, $200 \mu \mathrm{L}$ of methanol $(99 \%, \mathrm{v} / \mathrm{v})$ were dispensed to the wells, and kept for $20 \mathrm{~min}$ to fix the biofilms. The biofilms were then stained by introducing $100 \mu \mathrm{L}$ of crystal violet $(0.2 \%, \mathrm{w} / \mathrm{v})$ solution to the wells and keeping at room temperature for $15 \mathrm{~min}$. The excess or unbound crystal violet in the wells was removed by four-times washing with PBS. The crystal violet on the biofilm cells was extracted in $100 \mu \mathrm{L}$ of $95 \%$ ethanol, and their optical densities (OD) were measured, which yields a measure of biofilm formation (compared to the control). Measurements were performed in triplicate and repeated 3 times.

Previously reported biofilm viability assay methods were utilized to evaluate the effects of combination drugs on the viability of the biofilms produced by $S$. Typhimurium and $E$. coli $[23,36]$. In brief, sterile TSB broth of $2 \mathrm{~mL}$ were transferred to a Nunc ${ }^{\mathrm{TM}}$ Lab-Tek $^{\text {TM }}$ II Chambered Cover glass (ThermoFisher Scientific, Waltham, MA, United States), and diluted cultures of $S$. Typhimurium and $E$. coli were inoculated into the broth to a final concentration of $1 \times 10^{6} \mathrm{CFU} / \mathrm{mL}$. The Nunc ${ }^{\mathrm{TM}}$ Lab-Tek $^{\mathrm{TM}}$ II Chambered Cover glass which contain $S$. Typhimurium and E. coli cells were kept in a static incubator at $37^{\circ} \mathrm{C}$ until $48 \mathrm{~h}$ for biofilm formation. Every $24 \mathrm{~h}$, the TSB broth used in biofilm formation was replaced by fresh, sterile TSB broth. The supernatants and planktonic cells were discarded after incubating the bacteria for $48 \mathrm{~h}$, and the chambered cover glasses were washed by $1 \times$ PBS. Then, $2 \mathrm{~mL}$ of sterile TSB containing the test compounds alone or in combination (GA-ceftiofur, GA-ampicillin and hamamelitannin-erythromycin) at $1 / 4 \mathrm{MIC}, 1 / 2 \mathrm{MIC}$ and $1 \mathrm{MIC}$ concentrations were added. The biofilms were again kept in a static incubator at $37^{\circ} \mathrm{C}$ for $24 \mathrm{~h}$ to treat the developed-biofilm cells. After $24 \mathrm{~h}$ of exposure to the test compounds, the biofilms were again washed with sterile double distilled water (DDW) and stained with BacLight live/dead 
stain (ThermoFisher Scientific, Waltham, MA, United States). Confocal laser scanning microscope (CLSM) was used to scan the viable and nonviable biofilms. Imaging was performed with a Zeiss LSM 700 CLSM (Zeiss, Oberkochen, Germany) within the $488 \mathrm{~nm}$ excitation and 560-600 nm emission range. Zen 2009 software was used to execute image acquisition as well as subsequent image manipulation. Untreated biofilm was used as a control.

\section{Effect of antibacterial combinations on the motility of bacterial cells}

The swarming and swimming motilities of E. coli (ATCC 25922) and S. Typhimurium (ATCC 14028) in the presence of the combination drugs were evaluated according to previously published methods with slight modifications [37, 38]. The media used for the E. coli (ATCC 25922) swarming assay was composed of $0.8 \%$ Luria-Bertani (LB) supplemented with $0.5 \%$ glucose and $0.6 \%$ agar. Nutrient broth (NB) supplemented with $0.5 \%$ glucose and $0.5 \%$ agar was used for the evaluation of $S$. Typhimurium (ATCC 14028 ) swarming motility. The media used to evaluate $E$. coli swimming activity was composed of $1 \%$ tryptone broth supplemented with $0.5 \% \mathrm{NaCl}$ and $0.3 \%$ agar. Nutrient broth supplemented with $0.5 \%$ glucose and $0.25 \%$ agar was used as the media for the $S$. Typhimurium swimming motility assay. Molten agar plates were supplemented with $1 / 4 \mathrm{MIC}, 1 / 2 \mathrm{MIC}$ and $1 \mathrm{MIC}$ concentrations of test compounds alone or in combination (GA-ceftiofur, GA-ampicillin and hamamelitannin-erythromycin). A non-supplemented drug free plate was employed as the negative control. The plates were allowed to dry for $1 \mathrm{~h}$ and then $2 \mu \mathrm{L}$ of $E$. coli and $S$. Typhimurium cultures were inoculated onto the respective swarming and swimming agar plates. For both strains, swarm plates were kept at $37^{\circ} \mathrm{C}$ overnight, whereas swim plates were incubated at $37^{\circ} \mathrm{C}$ for $10 \mathrm{~h}$. After incubation, the swarm and swim zone diameters were measured using calibrated digital slide callipers (Mitotoyo, Japan), and photographs of the plates were captured.

\section{Cell viability in the presence of antibacterial agents}

The in vitro viability of Rattus norvegicus small intestine (IEC-6; American Type Culture Collection CRL1592, VA, United States) cell lines in the presence of GA, hamamelitannin, ampicillin, ceftiofur and erythromycin alone, and combinations of GA-ceftiofur, GA-ampicillin and hamamelitannin-erythromycin were evaluated according to standard EZ-cytox (EZ-1000; Daeillab Service Co. Ltd., Jeonju, South Korea) assay method. In brief, IEC- 6 cells were cultured at $37^{\circ} \mathrm{C}$ under a humidified atmosphere of $5 \%$ carbon dioxide $\left(\mathrm{CO}_{2}\right)$ in Dulbecco's Modified Eagle's medium (DMEM; ThermoFisher Scientific, Waltham, MA, United States) with $4 \mathrm{mM}$ L-glutamine (ThermoFisher Scientific, Waltham, MA, United States), adjusted to contain $1.5 \mathrm{~g} / \mathrm{L}$ sodium bicarbonate (Carolina Biological Supply Company, Burlington, NC, United States) and $4.5 \mathrm{~g} / \mathrm{L}$ glucose and supplemented with $0.1 \mathrm{Unit} / \mathrm{mL}$ bovine insulin $(90 \%)$ and FBS $(10 \%)$. The cells were subpassaged at a ratio of 1:5 twice a week. One hundred microliters of suspended cells $\left(2 \times 10^{4}\right.$ cells $/ \mathrm{mL}$ in their respective culture medium) were acclimated in 96 -well plates at $37^{\circ} \mathrm{C}$ under $5 \% \mathrm{CO}_{2}$ for $24 \mathrm{~h}$. The medium from each well was aspirated and the cells were washed twice. One hundred 
microliters of the test compounds at various concentrations in their respective culture medium were dispensed into each well and the cells in the drug-supplemented medium were allowed to incubate at 37 ${ }^{\circ} \mathrm{C}$ under $5 \% \mathrm{CO}_{2}$ for $24 \mathrm{~h}$. A total of $10 \mu \mathrm{L}$ of EZ-cytox were added to each well. After incubation for $2 \mathrm{~h}$, the absorbances in each well were measured at $450 \mathrm{~nm}$ using a plate reader. Cells not treated with any drugs were assigned as the control. The cell viability (\%) was calculated by the following formula, and values of cell viability (\%) at different drug concentrations were used to determine the inhibitory concentration $50 \%\left(\mathrm{IC}_{50}\right)$ :

Cell viability $(\%)=(O D$ of drug-treated sample $/ O D$ of untreated sample $) \times 100$, where $O D$ is the optical density [39].

\section{Statistical analysis}

Results are presented as the means \pm standard deviation (SD) of triplicate analysis. Statistical analysis was carried out by using SAS software (SAS Institute Inc., Cary, NC, USA). One-way analysis of variance (ANOVA) followed by F-test was used to compare the results. Statistical significance was considered when the $P$-value was $<0.05$.

\section{Results}

\section{Antibacterial activities of commercial antibiotics and phenolic compounds}

Antibacterial activities of different antibiotics and phenolic compounds were evaluated against quality control (QC) strains of $E$. coli and $S$. Typhimurium, and clinical strains of $S$. Typhimurium. The MICs of the different antibiotics (amoxicillin, ampicillin, cefotaxime, ceftiofur, erythromycin, florfenicol, marbofloxacin, norfloxacin, penicillin $\mathrm{G}$ and Theamphenicol) against QC strains of E. coli and $S$. Typhimurium ranged from $0.125 \sim 256 \mu \mathrm{g} / \mathrm{mL}$ and $0.062 \sim 128 \mu \mathrm{g} / \mathrm{mL}$, respectively. In contrast, the MICs of the commercial antibiotics against the clinical isolates of $S$. Typhimurium ranged from 0.25 to $\geq 1024 \mu \mathrm{g} / \mathrm{mL}$. The results in Table 1 clearly demonstrate that the MICs of almost all of these commercial antibiotics against the clinical isolates were increased by several folds, which indicates that resistance has developed in these clinical strains [40-44]. The MICs of phenolic compounds (epicatechin, epicatechin gallate, epigallocatechin, GA and hamamelitannin) against the QC strains and clinical isolates of $S$. Typhimurium ranged from 256 to $\geq 1024 \mu \mathrm{g} / \mathrm{mL}$, with GA being the most potent among all the compounds. The MICs of the phenolic compounds against the QC strains of $E$. coli ranged from $512 \sim 2048.00 \mu \mathrm{g} / \mathrm{mL}$.

\section{In vitro synergy with commercial antibacterials}

Checkerboard microdilution assays were performed to evaluate the combination antibacterial interactions of the commercial antibiotics with the phenolic compounds. The results of the combined activities are 
presented in Table 2. Synergistic effects against $E$. coli were obtained from the combinations of thiamphenicol and GA (FICl: 0.281), erythromycin and hamamelitannin (FICl: 0.375), and thiamphenicol and hamamelitannin (FICl: 0.50). The combination of erythromycin and epicatechin gallate against $S$. Typhimurium also showed synergistic antibacterial effects (FICl: 0.50). Moreover, additive effects were obtained from 16 and 17 combinations, respectively against $S$. Typhimurium (FICl: 0.502 0.750) and $E$. coli (FICl: $0.502 ~ 0.625)$. The rest of the combinations showed indifferent effects against both bacteria, with no antagonistic effects observed from any of the combinations. GA-ampicillin, GA-ceftiofur and hamamelitannin-erythromycin combinations those had synergistic or additive antibacterial effects respectively against $E$. coli, S. Typhimurium and $E$. coli were selected for further study depending on both the clinical and commercial importance.

\section{Effects of combination drugs on time- and concentration-dependent inhibition}

The inhibitory effects of the combination antibacterials on bacterial growth rates over time are presented in Figure 1. The growth rate of $S$. Typhimurium (ATCC 14028) was approximately the same when a 1 MIC concentration of GA was supplemented into the culture, and the cell density increased by approximately 1 -fold at $24 \mathrm{~h}$ compared to the density at the time of inoculation (Figure 1a). The bacterium in the presence of $1 \mathrm{MIC}$ ceftiofur showed complete inhibition within $8 \mathrm{~h}$, after which log phase was initiated. Finally, after $24 \mathrm{~h}$, the cell density reached a level 1-fold higher than its initial density. In contrast, the cell number in the drug-free control culture increased by approximately 5 -fold within $6 \mathrm{~h}$, and the same cell density was sustained out to $24 \mathrm{~h}$ of incubation. Treatment with the antibacterial combination ( $1 \mathrm{MIC}$ of both ceftiofur and GA) completely inhibited the bacterial growth by $12 \mathrm{~h}$, after which time the bacteria gradually revived and finally reached a cell density at $24 \mathrm{~h}$ that was 2 -fold less than its initial 6-fold density. Sub-MIC levels of both drugs in combination prevented this increase in growth such that the final cell densities at $24 \mathrm{~h}$ were almost the same as their initial cell densities.

At $24 \mathrm{~h}$, the density of hamamelitannin (1MIC)-treated E. coli (ATCC 25922) cells was approximately 6fold less than the drug-free control. The growth of the $E$. colicells was also inhibited more than 6-fold at $24 \mathrm{~h}$ in the presence of erythromycin (1MIC) compared to the control. Compared to the control, approximately 5 -fold less growth was observed after treating this bacterium for $24 \mathrm{~h}$ with sub-MIC levels of antibacterial combinations ( $1 / 2 \mathrm{MIC}$ of both hamamelitannin and erythromycin). Moreover, the $1 / 4 \mathrm{MIC}$ of both drugs together inhibited the growth by approximately 4-fold, which demonstrated the potential of this combination drug for bacterial inhibition.

1. coli (ATCC 25922) cultures incubated with a $1 \mathrm{MIC}$ concentration of GA for $24 \mathrm{~h}$ showed approximately 5 -fold less growth than the drug-free control. Compared to the control, the growth of the $E$. coli cells was also inhibited by approximately 6 -fold at $24 \mathrm{~h}$ in the presence of ampicillin (1MIC). Approximately 5 -fold less growth was observed compared to the control after culturing this bacterium for $24 \mathrm{~h}$ with sub-MIC levels of the antibacterial combination $(1 / 2 \mathrm{MIC}$ of both $\mathrm{GA}$ and ampicillin). 


\section{Effects of combination drugs on the morphology of bacterial cells}

The ultrastructural morphologies of $S$. Typhimurium (ATCC 14028) treated with the combination of GA and ceftiofur and Escherichia coli (ATCC 25922) treated with 2 drug combinations (hamamelitanninerythromycin and GA-ampicillin) were studied to assess whether the combination drugs had any impact on the cellular architecture. The representative SEM images of GA and ceftiofur-treated $S$. Typhimurium cells are shown in Figure 2. The SEM images revealed that untreated and GA (1MIC)-treated $S$. Typhimurium cells had rod-like shape and were separated with perfect symmetry. In addition, binary fission of the bacteria was evident in the SEM images (Figure 2a and c). The cells treated with ceftiofur alone or in combination with GA were found in a long rope-like shape, and no binary fission was evident, which is completely different from control cells. None of the cells were pitted, deformed or broken and the antibacterials had no effect on the cell wall or cytoplasmic membrane of the bacteria. The $E$. colicells treated with hamamelitannin-erythromycin and GA-ampicillin combinations also showed similar changes in cell length and binary fission without any effects on the cell wall or cytoplasmic membrane (data not shown).

\section{Effects of combination drugs on biofilm inhibition and viability}

S. Typhimurium (ATCC 14028) biofilm formation in the presence of the GA-ceftiofur drug combination and E. coli (ATCC 25922) biofilm formation in the presence of the hamamelitannin-erythromycin and GAampicillin drug combinations were evaluated using a static biofilm assay. The effects of the combination antibacterials on the growth of planktonic and biofilm cells of $S$. Typhimurium and $E$. coli are shown in Figure 3. The inhibition of both planktonic and biofilm cells of these bacteria was more induced by the combination drugs than by the individual drugs in most cases. The $1 / 4 \mathrm{MIC}$ of the commercial antibiotics could significantly inhibit $S$. Typhimurium and $E$. coli biofilm formation when a lower amount of the respective phenolic compounds were applied together with these antibiotics.

The viability of the biofilms in the presence of the combination antibacterials was determined by staining the biofilms with BacLight live/dead stain and imaging with a CLSM. The reduction in biofilm viability with the combination antibacterial treatments is demonstrated by the results obtained with the CLSM. Figure 4 shows the CLSM images of $S$. Typhimurium and $E$. coli biofilms formed on a glass surface and treated with or without the combination antibacterials. The confocal micrograph of $48 \mathrm{~h} S$. Typhimurium and $E$. coli biofilms treated with combination antibacterials for $24 \mathrm{~h}$ displays a lower proportion of live cells (cells that are stained green) than those observed in the untreated controls. It is clearly visible that almost all the cells were alive in the control biofilm, while most of the cells were dead (cells that are stained red) after treatment with the combination antibacterials. 


\section{Effects of combination drugs on the motility of bacterial cells}

The effects of the antibacterial combinations on the swimming and swarming motilities of $S$. Typhimurium (ATCC 14028) and E. coli (ATCC 25922) were evaluated. Representative photographs of drug-treated swim and swarm plates are displayed in Figure 5. Table 3 shows the diameters of the swim and swarm zones. The results demonstrated that the hamamelitannin-erythromycin combination and the GA-ampicillin combination significantly inhibited both the swimming and the swarming motilities of $E$. coli. Similarly, the swimming and swarming motilities of $S$. Typhimurium were noticeably inhibited by the GA-ceftiofur combination. Moreover, the combination antibacterials showed better inhibitions of swimming and swarming motilities at sub-MIC concentrations compared to their individual effects at MIC concentrations.

\section{Effects of combination drugs on the viability of IEC-6 cells}

The effects of GA and hamamelitannin alone, and GA-ampicillin, GA-ceftiofur and hamamelitanninerythromycin combinations on the viability of IEC- 6 cells are shown in Table 4 and Additional file 1 . The $\mathrm{IC}_{50}$ of GA and hamamelitannin in IEC-6 cells were $564.55 \mu \mathrm{M}$ and $988.54 \mu \mathrm{M}$, respectively. The IC $\mathrm{I}_{50}$

values of GA are more in presence of commercial antibiotics (ampicillin and ceftiofur) than $\mathrm{IC}_{50}$ values of $\mathrm{GA}$ alone (in absence of commercial antibiotics). In contrast, $\mathrm{IC}_{50}$ values of ampicillin and ceftiofur are less in presence of GA than $\mathrm{IC}_{50}$ values of those commercial antibiotics alone (in absence of GA). However, hamamelitannin, erythromycin and their combination showed opposite trend in the viability of IEC-6 cells.

\section{Discussion}

The development of alternative antimicrobial drugs is urgently needed to combat infectious diseases associated with resistant pathogens $[45,46]$. The in vitro activities of the tested phenolic compounds against resistant strains of Salmonella Typhimurium (Table 1) reflects that some of these compounds could be good candidates to minimize the development of bacterial resistance and to ensure clinical treatment of bacterial infections in farm animals. In the present study, the MIC results demonstrated the antibacterial activities of the phenolic compounds against all the tested strains of $S$. Typhimurium and $E$. coli, which have been shown to be resistant to one to eight out of ten currently available antibiotics (Table 1). The potentials of these phenolic compounds were further explored through their combined interactions with commercial antibiotics, where hamamelitannin possessed synergistic effects with thiamphenicol and erythromycin against $E$. coli. Further, epicatechin gallate with erythromycin, and GA with thiamphenicol demonstrated synergistic effects against $S$. Typhimurium and $E$. coli, respectively. The time- and concentration-dependent inhibition assays also exposed that hamamelitanninerythromycin and GA-ampicillin combinations, and GA-ceftiofur combination more effectively inhibited the growth of $E$. coli and $S$. Typhimurium, respectively than the antibiotics alone. Furthermore, the 
combinations of these phenolic compounds and commercial antibiotics demonstrated improved inhibition of biofilm formation and motility in S. Typhimurium and E. coli.

The MICs of the 5 phenolic compounds (epicatechin, epicatechin gallate, epigallocatechin, GA and hamamelitannin) were investigated against QC strains of $S$. Typhimurium and $E$. coli, and 5 clinical strains of $S$. Typhimurium. It has been reported that GA can restrain the growth of many bacteria, including methicillin-sensitive S. aureus, MRSA, E. coli, P. aeruginosa, and Salmonella typhi [47]. The results in Table 1 indicate that GA possessed the strongest antibacterial activity among these phenolic compounds, followed by epigallocatechin, hamamelitannin, epicatechin gallate and epicatechin. The MIC values of GA against $S$. Typhimurium $(256 \mu \mathrm{g} / \mathrm{mL})$ and $E$. coli $(1024 \mu \mathrm{g} / \mathrm{mL})$ in this study are lower than those reported previously $(2500 \mu \mathrm{g} / \mathrm{mL})$ [47]. The mean MICs of plant-derived epigallocatechin against $S$. Typhimurium and $E$. coli were reported to be $572 \pm 186$ and $733 \pm 121 \mu \mathrm{g} / \mathrm{mL}$, respectively [48]. The MIC values of pure epigallocatechin against $S$. Typhimurium $(512 \mu \mathrm{g} / \mathrm{mL})$ and $E$. coli $(512 \mu \mathrm{g} / \mathrm{mL})$ in our study were lower than the previously reported MIC values [48]. This lower MIC value of pure epigallocatechin against $S$. Typhimurium and $E$. coli in our study compared to the MIC value of plantderived epigallocatechin in the previous study is might be because of the purity of the compound used. However, the MIC values of plant-derived epigallocatechin against $S$. Typhimurium and E. coli were comparable with the results of our study. Likewise, the MICs of epicatechin against $S$. Typhimurium and E. coli were $2500 \mu \mathrm{g} / \mathrm{mL}$, which demonstrates the similarity between our results and previously published results [47].

It is always recommended to treat bacterial infections with a combination of antimicrobial agents to prevent the development of drug resistance and to improve efficacy. Drug combinations with synergistic interactions are generally considered to be more effective and, therefore, preferable [49]. Incidentally, synergistic effects were obtained from the combinations of thiamphenicol and GA (FICl: 0.281), erythromycin and hamamelitannin (FICl: 0.375), and thiamphenicol and hamamelitannin (FICl: 0.50) against $E$. coli. The combination of erythromycin and epicatechin gallate against $S$. Typhimurium also showed synergistic antibacterial effects (FICl: 0.50). Moreover, additive effects were obtained from 16 and 17 combinations respectively against $S$. Typhimurium (FICl: 0.502 0.750), and E. coli (FICl: $0.502 \sim 0.625)$. The rest of the combinations had indifferent effects against these bacteria. Excellent in vitro activity combined with the synergistic effects with other antibacterial drugs underscores the potential utility of these phenolic compounds for the treatment of E. coli and $S$. Typhimurium-associated infections in farm animals. The combinations of GA and ceftiofur, hamamelitannin and erythromycin, and GA and ampicillin, which have synergistic or additive antibacterial effects against $S$. Typhimurium and $E$. coli were selected for further studies depending on both the clinical and commercial importance.

Time-kill assays are useful for the evaluation of the pharmacodynamic characteristics of new antimicrobial agents and to determine whether the effects of antibacterials are bacteriostatic or bactericidal [50]. According to our results, GA and hamamelitannin alone or in combination with ceftiofur, ampicillin and erythromycin show bacteriostatic activity against the tested bacteria, as a reduction $\geq 99.9 \%$ of the inoculum was not observed compared to the growth control. At $1 / 2 \mathrm{MIC}$, both GA and 
ceftiofur in combination were able to inhibit $S$. typhimurium in the first $8 \mathrm{~h}$ of incubation, similarly the $1 \mathrm{MIC}$ of both drugs in combination demonstrated complete inhibition within the first $8 \mathrm{~h}$. The bacteria treated with $1 / 2 \mathrm{MIC}$ and $1 \mathrm{MIC}$ concentrations of the combination antibacterials started their log phase after the first $8 \mathrm{~h}$ and $12 \mathrm{~h}$ of incubation, respectively. At the end of the incubation period $(24 \mathrm{~h})$, a greater than 3-fold reduction in the inoculum concentration with $1 / 2 \mathrm{MIC}$ of GA and ceftiofur and an approximately 7-fold lower inoculums concentration with 1MIC of GA and ceftiofur were achieved in contrast to the control. The $1 \mathrm{MIC}$ of hamamelitannin and erythromycin together inhibited the growth of $E$. coli completely within the first $12 \mathrm{~h}$, after which the bacteria started to revive. After the incubation period, the inoculum concentrations were reduced by several-fold compared to the control for the bacteria treated with GA and hamamelitannin alone or in combination with ceftiofur, erythromycin or ampicillin, indicating that these phenolic compounds alone and in combination with ceftiofur, erythromycin and ampicillin have bacteriostatic effects.

In investigating antibacterial effects it is also essential to evaluate changes in the bacterial cell morphology, membrane permeability and integrity, and surface characteristics [51, 52]. The physiological and morphological changes in E. coli and S. Typhimurium were observed by SEM after treatment with GA and hamamelitannin alone and in combination with ceftiofur, erythromycin and ampicillin. The results showed a direct effect of the combination antibacterials on the tested pathogens. The treated bacterial cells showed obvious morphological changes compared to untreated cells. Almost all treated bacterial cells were found as long and ropelike, with no binary fission, which is completely different from the untreated control cells. These observations indicated that the combination antibacterials had a major effect on the bacterial cell division. To exhibit this effect, drug combinations possibly induced the expression of SOS operon by damaging DNA or by blocking DNA replication, and/or may inhibited or mutated penicillin-binding proteins (PBP) [53-55].

S. Typhimurium (ATCC 14028) biofilm formation in the presence of the GA-ceftiofur combination; and $E$. coli (ATCC 25922) biofilm formation in the presence of the hamamelitannin-erythromycin and GAampicillin combinations were evaluated using a static biofilm assay. The inhibition of both planktonic and biofilm cells of these bacteria was induced by the combination drugs more than the individual drugs in most cases. The surviving and dead biofilm populations in the presence of the combination antibacterials were determined by imaging the BacLight live/dead-stained biofilm by CLSM. These results revealed that in addition to being bacteriostatic, the GA-ceftiofur, hamamelitannin-erythromycin and GAampicillin combinations appeared to act against the biofilm matrix. The large effect of the GA-ceftiofur and GA-ampicillin combinations against the biofilm cells of $S$. Typhimurium and $E$. coli, respectively, might be due to the small molecular size of GA $(170.12 \mathrm{~g} / \mathrm{mol})$, which easily penetrates into the biofilm. Subsequently, these combination antibacterials seem to destroy the biofilm matrix, resulting in the detachment of cells and thus the biofilm cells become more exposed and susceptible.

Motility is one of the pathogenic phenotypes of bacteria that contribute to the migration and dispersion of bacteria and their escape from the host immune response [37]. Flagella are known to be involved in swimming motility and play a role in biofilm formation, as well as swarming motility [48]. Recent reports 
mentioned that, similar to biofilms, swarming cells also show a higher degree of resistance to a variety of antibiotics $[56,57]$. In this study, we investigated the ability of the GA-ceftiofur, hamamelitanninerythromycin and GA-ampicillin combinations to inhibit the swarming and swimming activities of $S$. Typhimurium and E. coli. The results (Table 3 ) showed significant inhibition of swimming and swarming motilities with the addition of GA-ceftiofur, hamamelitannin-erythromycin and GA-ampicillin combinations. The lack of swimming and swarming motilities in the presence of the combination antibacterials suggest that these agents might have some effects on flagella-related processes, namely, flagella biosynthesis, rotation, and chemotaxis, which may lead to decreased swimming and swarming activities.

The evaluation of the safety/toxicity profiles of any drug is desirable and an essential part of the investigation of the pharmacological effects. Virtually all organs and tissues are exposed, once the ingested drugs cross the intestinal wall [58]. Many studies have demonstrated that insignificant amounts of orally administered phenolic compounds such as GA and hamamelitannin are absorbed through the gastrointestinal tract due to its low membrane permeability and poor water solubility $[59,60]$. Therefore, the pharmacological or toxicological effects of these phenolic compounds can be largely explained in terms of their local effects. Moreover, this study found synergistic effects of these phenolic compounds against enteric bacteria ( $E$. coli and $S$. Typhimurium). Likewise, these antibacterial combinations may also be applicable in the eradication of invasive enteric pathogens in the gastrointestinal tract prior to mucosal penetration. Administration of drug through oral route can be more logical to treat these enteric becteria. Thus, oral administration of these phenolic compounds can exert their antibacterial effects within the gastrointestinal lumen and will be unable to reach in systemic circulation as well as other vital organs. Based on this explanation, oral administration of these compounds will have no chance to harm other organs except the gastrointestinal tract. Therefore, investigating the viability of intestinal cell is the particular interest of this study. Hence, the cytotoxic effects of GA and hamamelitannin alone, and GAceftiofur, hamamelitannin-erythromycin and GA-ampicillin combinations were investigated in IEC- 6 cell lines. The $\mathrm{IC}_{50}$ values of GA and hamamelitannin were $564.55 \mu \mathrm{M}$ and $988.54 \mu \mathrm{M}$ in IEC- 6 cells, respectively. The effects of GA and hamamelitannin on cell viability were evaluated previously with different cell lines and found to have cytoprotective effects or no adverse effects in cell viability [61, 62]. Thus, the $\mathrm{IC}_{50}$ values of GA-ceftiofur, hamamelitannin-erythromycin and GA-ampicillin combinations obtained in this study are logical and reliable.

\section{Conclusion}

Together with all the promising in vitro assay findings, it is concluded that gallic acid and hamamelitannin alone, and in combination with commercial antibiotics can be promising, potent and noble candidates to eradicate pathogenic $S$. Typhimurium and $E$. coli. The effects of gallic acid and hamamelitannin are bacteriostatic, and the use of gallic acid-ceftiofur combination; and hamamelitanninerythromycin and gallic acid-ampicillin combinations can more effectively interfere with the biofilms of $S$. Typhimurium and E. coli, respectively than the antibiotics alone, which is crucial to develop new 
antimicrobials and/or improve the efficacy of existing antimicrobials for reducing the pathogenicity associated with these bacteria. This study suggest that gallic acid-ceftiofur combination can be potential medication to treat $S$. Typhimurium-associated diarrhea and prevent $S$. Typhimurium-associated bloodstream infections (e.g.: fever) in farm animals. Hamamelitannin-erythromycin and gallic acid-ampicillin combinations can be effective in restricting $E$. colicontamination in farm animals, and ultimately its transmission from animal to human. Further study is recommended to confirm their efficacy and safety in in vivo systems for enhancing their safe and effective utilization as medications.

\section{Abbreviations}

AMP: ampicillin; CDC: canter for disease control and prevention; CEF: ceftiofur; CLSI: clinical and laboratory standard institute; CLSM: confocal laser scanning microscope; DDW: double-distilled water; DMEM: dulbecco's modified eagle's medium; ERY: erythromycin; FIC: Fractional inhibitory concentration; FICl: FIC index; GA: gallic acid; GIC $_{50}$ : 50\% growth inhibition concentration; HAMA: hamamelitannin; IC $_{50}$ : inhibitory concentration 50\%; MDR: multidrug-resistant; MHA: mueller hinton agar; MHB: mueller hinton broth; MIC: minimum inhibitory concentration; NB: nutrient broth; NTME: Nymphaea tetragona 50\% methanol extract; OD: optical density; PBS: phosphate buffer saline; QC: quality control; QS: quorum sensing; SEM: scanning electronic microscope; TSB: trypticase soy broth; WHO: world health organization.

\section{Declarations}

\section{Competing Interests}

None of the authors have any conflicts of interest to declare.

\section{Availability of Data and Materials}

Data will be shared upon request to the corresponding author.

\section{Ethics Approval and Consent to Participate}

All procedures have been approved by the Bioethical Committee of Animal and Plant Quarantine Agency, Republic of Korea.

\section{Authors' Contributions}

MAH conceived the study, and involved in conception, design, acquisition of data, analysis, interpretation, drafting and critically revising the manuscript; JWK and HCP were involved in some of the experiments and reviewed the manuscript; JWK, SUP and KJL analyzed the data and approved the final version of the manuscript. All authors read and approved the final manuscript. 
${ }^{1}$ Veterinary Drugs \& Biologics Division, Animal and Plant Quarantine Agency, Gimcheon-si 39660, Republic of Korea. ${ }^{2}$ Laboratory of Veterinary Pharmacokinetics and Pharmacodynamics, College of Veterinary Medicine, Kyungpook National University, Bukgu, Daegu 41566, Republic of Korea.

\section{Acknowledgements}

The authors would like to thank all members of the laboratory of antibiotics and therapeutics, Veterinary Drugs \& Biologics Division, Animal and Plant Quarantine Agency for their support during these studies.

\section{Funding}

This study was supported by Veterinary Science Research Project grants from the Korean Animal and Plant Quarantine Agency (Grant no. B-1543073-2017-17-0101).

\section{References}

1. Wiethoelter AK, Beltrán-Alcrudo D, Kock R, Mor SM. Global trends in infectious diseases at the wildlife-livestock interface. Proc Natl Acad Sci U S A. 2015;112(31):9662-7. doi: 10.1073/pnas.1422741112

2. Farooqui A, Khan A, Borghetto I, Kazmi SU, Rubino S, Paglietti B. Synergistic antimicrobial activity of Camellia sinensis and Juglans regia against multidrug-resistant bacteria. PLoS One. 2015;10(2):e0118431. doi: 10.1371/journal.pone.0118431

3. Golkar Z, Bagasra O, Pace DG. Bacteriophage therapy: a potential solution for the antibiotic resistance crisis. J Infect Dev Ctries. 2014;8(2):129-36. doi: 10.3855/jidc.3573

4. Gould IM, Bal AM. New antibiotic agents in the pipeline and how they can help overcome microbial resistance. Virulence. 2013;4(2):185-91. doi: 10.4161/viru.22507

5. Wright GD. Something old, something new: revisiting natural products in antibiotic drug discovery. Can J Microbiol. 2014;60(3):147-54. doi: 10.1139/cjm-2014-0063

6. Sengupta S, Chattopadhyay MK, Grossart HP. The multifaceted roles of antibiotics and antibiotic resistance in nature. Front Microbiol. 2013;4:47. doi: 10.3389/fmicb.2013.00047

7. Antibiotic Resistance Threats in the United States. Centers for Disease Control and Prevention, U.S. Department of Health and Human Services. 2013. https://www.cdc.gov/drugresistance/pdf/arthreats-2013-508.pdf. Accessed 26 Mar 2019

8. Shrestha L. Life expectancy in the United States. Congressional research service report. 2005. https://www.research.policyarchive.org/2355.pdf. Accessed 26 Mar 2019

9. Viswanathan VK. Off-label abuse of antibiotics by bacteria. Gut Microbes. 2014;5(1):3-4. doi: $10.4161 /$ gmic.28027

10. Read AF, Woods RJ. Antibiotic resistance management. Evol Med Public Health. 2014;2014(1):147. doi: 10.1093/emph/eou024

11. The antibiotic alarm. Nature. 2013;495(7440):141. doi: 10.1038/495141a 
12. Lushniak BD. Antibiotic resistance: a public health crisis. Public Health Rep. 2014;129(4):314-6. doi: 10.1177/003335491412900402

13. Gross M. Antibiotics in crisis. Curr Biol. 2013;23(24):R1063-5. doi: 10.1016/j.cub.2013.11.057

14. Piddock LJ. The crisis of no new antibiotics--what is the way forward? Lancet Infect Dis. 2012;12(3):249-53. doi: 1016/S1473-3099(11)70316-4

15. Bartlett JG, Gilbert DN, Spellberg B. Seven ways to preserve the miracle of antibiotics. Clin Infect Dis. 2013;56(10):1445-50. doi: 10.1093/cid/cit070

16. Michael CA, Dominey-Howes D, Labbate M. The antimicrobial resistance crisis: causes, consequences, and management. Front Public Health. 2014;2:145. doi: 10.3389/fpubh.2014.00145

17. Rossolini GM, Arena F, Pecile P, Pollini S. Update on the antibiotic resistance crisis. Curr Opin Pharmacol. 2014;18:56-60. doi: 10.1016/j.coph.2014.09.006

18. Tacconelli E, Magrini N. Global priority list of antibiotic-resistant bacteria to guide research, discovery, and development of new antibiotics. World Health Organization, Geneva. 2017.

https://www.who.int/medicines/publications/WHO-PPL-Short_Summary_25Feb-ET_NM_WHO.pdf? ua=1. Accessed 26 Mar 2019

19. Courtney CM, Goodman SM, Nagy TA, Levy M, Bhusal P, Madinger NE, Detweiler CS, Nagpal P, Chatterjee A. Potentiating antibiotics in drug-resistant clinical isolates via stimuli-activated superoxide generation. Sci Adv. 2017;3(10):e1701776. doi: 10.1126/sciadv.1701776

20. Patra JK, Baek KH. Antibacterial activity and synergistic antibacterial potential of biosynthesized silver nanoparticles against foodborne pathogenic bacteria along with its anticandidal and antioxidant effects. Front Microbiol. 2017;8:167. doi: 10.3389/fmicb.2017.00167

21. Acharyya S, Sarkar P, Saha DR, Patra A, Ramamurthy T, Bag PK. Intracellular and membranedamaging activities of methyl gallate isolated from Terminalia chebula against multidrug-resistant Shigella J Med Microbiol. 2015;64(8):901-9. doi: 10.1099/jmm.0.000107

22. Ozcan T, Akpinar-Bayizit A, Yilmaz-Ersan L, Delikanli B. Phenolics in human health. Int $\mathrm{J}$ Chem Eng Appl. 2014;5(5):393-6. doi: 10.7763/IJCEA.2014.V5.416

23. Hossain MA, Lee SJ, Park JY, Reza MA, Kim TH, Lee KJ, Suh JW, Park SC. Modulation of quorum sensing-controlled virulence factors by Nymphaea tetragona (water lily) extract. J Ethnopharmacol. 2015;174:482-91. doi: 10.1016/j.jep.2015.08.049

24. Hossain MA, Park JY, Kim JY, Suh JW, Park SC. Synergistic effect and antiquorum sensing activity of Nymphaea tetragona (water lily) extract. Biomed Res Int. 2014;2014:562173. doi: $1155 / 2014 / 562173$

25. Pimenta ADL, Chiaradia-Delatorre LD, Mascarello A, de Oliveira KA, Leal PC, Yunes RA, de Aguiar CB, Tasca Cl, Nunes RJ, Smania A Jr. Synthetic organic compounds with potential for bacterial biofilm inhibition, a path for the identification of compounds interfering with quorum sensing. Int $\mathrm{J}$ Antimicrob Agents 2013;42(6):519-23. doi: 10.1016/j.jjantimicag.2013.07.006

26. Hossain MA, Lee SJ, Park NH, Mechesso AF, Birhanu BT, Kang J, Reza MA, Suh JW, Park SC. Impact of phenolic compounds in the acyl homoserine lactone-mediated quorum sensing regulatory 
pathways. Sci Rep. 2017;7:10618. doi: 10.1038/s41598-017-10997-5

27. Birhanu BT, Park NH, Lee SJ, Hossain MA, Park SC. Inhibition of Salmonella Typhimurium adhesion, invasion, and intracellular survival via treatment with methyl gallate alone and in combination with marbofloxacin. Vet Res. 2018;49(1):101. doi: 10.1186/s13567-018-0597-8

28. Yong YC, Zhong JJ. Impacts of quorum sensing on microbial metabolism and human health. Adv Biochem Eng Biotechnol. 2013;131:25-61. doi: 10.1007/10_2012_138

29. Wang Y. The anti-oxidation and anti-microbial activities of tea polyphenols and its increased reagents. J Biol. 2007;24:54-6.

30. Methods for Dilution Antimicrobial Susceptibility Tests for Bacteria that Grow Aerobically. CLSI Approved Standards M7-A5. Clinical and Laboratory Standards Institute, Wayne. 2000. https://clsi.org/media/1928/m07ed11_sample.pdf. Accessed 26 Mar 2019.

31. Reddy VM, Einck L, Nacy CA. In vitro antimycobacterial activities of capuramycin analogues. Antimicrob Agents Chemother. 2008;52(2):719-21. doi: 1128/AAC.01469-07

32. Shalit I, Shadkchan Y, Samra Z, Osherov N. In vitro synergy of caspofungin and itraconazole against Aspergillus: MIC versus minimal effective concentration end points. Antimicrob Agents Chemother. 2003;47(4):1416-8. doi:10.1128/AAC.47.4.1416-1418.2003

33. Murtey M, Ramasamy P. Sample preparations for scanning electron microscopy-life sciences. In: Janecek M, Kral R, editors. Modern Electron Microscopy in Physical and Life Sciences. IntechOpen. London, United Kingdom, 2016. P. 161-85.

34. McGrath DM, Barbu EM, Driessen WH, Lasco TM, Tarrand JJ, Okhuysen PC, Kontoyiannis DP, Sidman RL, Pasqualini R, Arap W. Mechanism of action and initial evaluation of a membrane active all-Denantiomer antimicrobial peptidomimetic. Proc Natl Acad Sci USA. 2013;110(9):3477-82. doi: $10.1073 /$ pnas. 1221924110

35. Zhao T, Liu Y. N-acetylcysteine inhibit biofilms produced by Pseudomonas aeruginosa. BMC Microbiol 2010;10:140. doi: 10.1186/1471-2180-10-140

36. Periasamy S, Joo HS, Duong AC, Bach TH, Tan VY, Chatterjee SS, Cheung GY, Otto M. How Staphylococcus aureus biofilms develop their characteristic structure. Proc Natl Acad Sci USA. 2012;109(4):1281-6. doi: 10.1073/pnas.1115006109

37. Zhuang Y, Chen W, Yao F, Huang Y, Zhou S, Li H, Zhang Z, Cai C, Gao Y, Peng Q. Short-term pretreatment of sub-inhibitory concentrations of gentamycin inhibits the swarming motility of Escherichia coli by down-regulating the succinate dehydrogenase gene. Cell Physiol Biochem. 2016;39(4):1307-16. doi: 10.1159/000447835

38. Kim W, Killam T, Sood V, Surette MG. Swarm-cell differentiation in Salmonella enterica serovar Typhimurium results in elevated resistance to multiple antibiotics. J Bacteriol. 2003;185(10):3111-7. doi: 10.1128/JB.185.10.3111-3117.2003

39. Lai LH, Fu QH, Liu Y, Jiang K, Guo QM, Chen QY, Yan B, Wang QQ, Shen JG. Piperine suppresses tumor growth and metastasis in vitro and in vivo in a $4 \mathrm{~T} 1$ murine breast cancer model. Acta Pharmacol Sin. 2012;33(4):523-30. doi: 10.1038/aps.2011.209 
40. Performance Standards for Antimicrobial Disk and Dilution Susceptibility Testing for Bacteria Isolated From Animals. CLSI Approved Standards M31-A3. Clinical and Laboratory Standards Institute, Wayne. 2008.

https://www.dbt.univr.it/documenti/Occorrenzalns/matdid/matdid485539.pdf. Accessed 26 Mar 2019.

41. Breakpoint tables for interpretation of MICs and zone diameters. Version 9.0. European Committee on Antimicrobial Susceptibility Testing, Basel. 2019. http://www.eucast.org/clinical_breakpoints/. Accessed 26 Mar 2019.

42. Sanhueza L, Melo R, Montero R, Maisey K, Mendoza L, Wilkens M. Synergistic interactions between phenolic compounds identified in grape pomace extract with antibiotics of different classes against Staphylococcus aureus and Escherichia coli. PLoS ONE. 2017;12(2):e0172273. doi: 10.1371/journal.pone. 0172273

43. Clinical Microbiology and Infection. Statement 1996 CA-SFM Zone sizes and MIC breakpoints for non-fastidious organisms. Clin Microbiol Infect. 1996;2 Suppl 1: S46-9. doi: 10.1111/j.14690691.1996.tb00875.x

44. Wei CF, Chang SK, Shien JH, Kuo HC, Chen WY, Chou CC. Synergism between two amphenicol of antibiotics, florfenicol and thiamphenicol, against Staphylococcus aureus. Vet Rec.2016;178(13): doi: 10.1136/vr.103554

45. Berahou A, Auhmani A, Fdil N, Benharref A, Jana M, Gadhi CA. Antibacterial activity of Quercus ilex bark's extracts. J Ethnopharmacol. 2007;112(3):426-9. doi: 1016/j.jep.2007.03.032

46. Salomao K, Pereira PR, Campos LC, Borba CM, Cabello PH, Marcucci MC, De Castro SL. Brazilian propolis: correlation between chemical composition and antimicrobial activity. Evid Based Complement Alternat Med. 2008;5(3):317-24. doi: 10.1093/ecam/nem058

47. Fu L, Lu W, Zhou X. Phenolic compounds and in vitro antibacterial and antioxidant activities of three tropic fruits: persimmon, guava, and sweetsop. BioMed Res Int. 2016;2016:4287461. doi: $1155 / 2016 / 4287461$

48. Taguri T, Tanaka T, Kouno I. Antimicrobial activity of 10 different plant polyphenols against bacteria causing food-borne disease. Biol Pharm Bull. 2004;27:1965-9. doi: 1248/bpb.27.1965

49. Dubuisson T, Bogatcheva E, Krishnan MY, Collins MT, Einck L, Nacy CA, Reddy VM. In vitro antimicrobial activities of capuramycin analogues against non-tuberculous mycobacteria. $\mathrm{J}$ Antimicrob Chemother. 2010;65(12):2590-7. doi: 10.1093/jac/dkq372

50. Pfaller MA, Sheehan DJ, Rex JH. Determination of fungicidal activities against yeasts and molds: lessons learned from bactericidal testing and the need for standardization. Clin Microbiol Rev. 2004;17(2):268-80. doi: 10.1128/CMR.17.2.268-280.2004

51. Diao W-R, Hu Q-P, Zhang H, Xu J-G. Chemical composition, antibacterial activity and mechanism of action of essential oil from seeds of fennel (Foeniculum vulgare Mill.). Food Control. 2014;35(1):109-16. doi: 10.1016/j.foodcont.2013.06.056 
52. Sadiq MB, Tarning J, Aye Cho TZ, Anal AK. Antibacterial activities and possible modes of action of Acacia nilotica (L.) Del. against multidrug-resistant Escherichia coli and Salmonella. Molecules. 2017;22(1):47. doi: 10.3390/molecules22010047

53. Benson NR, Wong RMY, McClelland Analysis of the SOS Response in Salmonella entericaserovar Typhimurium Using RNA Fingerprinting by Arbitrarily Primed PCR. J Bacteriol. 2000;182(12):3490-7. doi: 10.1128/jb.182.12.3490-3497.2000

54. Jia M, Liu Z, Wu C, Zhang Z, Ma L, Lu X, Mao Y, Zhang H. Detection of Escherichia coli 0157:H7 and Salmonella enterica serotype Typhimurium based on cell elongation induced by beta-lactam antibiotics. Analyst. 2019;144(15):4505- doi: 10.1039/c9an00569b

55. Su IH, Ko WC, Shih CH, Yeh FH, Sun YN, Chen JC, Chen PL, Chang HC. Dielectrophoresis System for Testing Antimicrobial Susceptibility of Gram-Negative Bacteria to $\beta$-Lactam Antibiotics. Anal Chem. 2017;89(8):4635- doi: 10.1021/acs.analchem.7b00220

56. de la Fuente-Nunez C, Korolik V, Bains M, Nguyen U, Breidenstein EB, Horsman S, Lewenza S, Burrows L, Hancock RE. Inhibition of bacterial biofilm formation and swarming motility by a small synthetic cationic peptide. Antimicrob Agents Chemother. 2012;56(5):2696-704. doi:1128/AAC.00064-12

57. Lai S, Tremblay J, Deziel E. Swarming motility: a multicellular behaviour conferring antimicrobial resistance. Environ Microbiol. 2009;11(1):126-36. doi: 10.1111/j.1462-2920.2008.01747.x

58. Grenier B, Applegate TJ. Modulation of intestinal functions following mycotoxin ingestion: metaanalysis of published experiments in animals. Toxins. 2013;5(2):396-430. doi: 10.3390/toxins5020396

59. Bone K, Mills S. Principles and Practice of Phytotherapy. In: Modern Herbal Medicine. Second edition. Churchill Livingstone Elsevier, London, United Kingdom, P. 37.

60. Faralli A, Shekarforoush E, Mendes AC, Chronakis IS. Enhanced transepithelial permeation of gallic acid and (-)-epigallocatechin gallate across human intestinal caco-2 cells using electrospun xanthan nanofibers. 2019;11(4):155. doi: 10.3390/pharmaceutics11040155

61. Yang DJ, Moh SH, Son DH, You S, Kinyua AW, Ko CM, Song M, Yeo J, Choi YH, Kim KW. Gallic acid promotes wound healing in normal and hyperglucidic conditions. Molecules. 2016;21(7):E899. doi: 10.3390/molecules21070899

62. Masaki $\mathrm{H}$, Atsumi T, Sakurai $\mathrm{H}$. Protective activity of hamamelitannin on cell damage of murine skin fibroblasts induced by UVB irradiation. J Dermatol Sci. 1995;10(1):25-34. doi: 10.1016/09231811(95)93711-9

\section{Tables}

Table 1: Minimum inhibition concentration of commercial antibiotics and phenolic compounds against different strains; and antibacterial sensitivity profiles of Salmonella 
enterica serovarTyphimurium and Escherichia coli against some selected commercially available antibiotics. 
coli

\begin{tabular}{rrr}
\hline ATCC & V08-S- & V15-S \\
14028 & HA- & HA- \\
& $06-$ & $02-$ \\
& $(170)$ & $(210)$
\end{tabular}

\begin{tabular}{|c|c|c|c|c|c|c|c|c|}
\hline Amoxicillin & $\begin{array}{l}\text { MIC } \\
(\mu \mathrm{g} / \mathrm{mL})\end{array}$ & $\begin{array}{l}<0.5 \\
(\mathrm{~S})\end{array}$ & $\begin{array}{l}256 \\
(\mathrm{R})\end{array}$ & $1(\mathrm{~S})$ & $\begin{array}{l}256 \\
(\mathrm{R})\end{array}$ & $\begin{array}{l}256 \\
(\mathrm{R})\end{array}$ & $\begin{array}{l}256 \\
(\mathrm{R})\end{array}$ & $1(\mathrm{~S})$ \\
\hline Ampicillin & $\begin{array}{l}\text { MIC } \\
(\mu \mathrm{g} / \mathrm{mL})\end{array}$ & $1(\mathrm{~S})$ & $\begin{array}{l}512 \\
(\mathrm{R})\end{array}$ & $\begin{array}{l}512 \\
(\mathrm{R})\end{array}$ & $\begin{array}{l}512 \\
(\mathrm{R})\end{array}$ & $\begin{array}{l}512 \\
(\mathrm{R})\end{array}$ & $\begin{array}{l}512 \\
(\mathrm{R})\end{array}$ & $2(\mathrm{~S})$ \\
\hline Cefotaxime & $\begin{array}{l}\text { MIC } \\
(\mu \mathrm{g} / \mathrm{mL})\end{array}$ & $\leq 2(\mathrm{~S})$ & $\leq 2(\mathrm{~S})$ & $\leq 2(\mathrm{~S})$ & $\begin{array}{l}512 \\
(\mathrm{R})\end{array}$ & $\begin{array}{l}128 \\
(\mathrm{R})\end{array}$ & $\begin{array}{l}128 \\
(\mathrm{R})\end{array}$ & $0.125(\mathrm{~S})$ \\
\hline Ceftiofur & $\begin{array}{l}\text { MIC } \\
(\mu \mathrm{g} / \mathrm{mL})\end{array}$ & $<1(\mathrm{~S})$ & $<1(\mathrm{~S})$ & $1(\mathrm{~S})$ & $\begin{array}{l}128 \\
(\mathrm{R})\end{array}$ & $64(\mathrm{R})$ & $64(\mathrm{R})$ & $1(\mathrm{~S})$ \\
\hline Erythromycin & $\begin{array}{l}\text { MIC } \\
(\mu \mathrm{g} / \mathrm{mL})\end{array}$ & $\begin{array}{l}128 \\
(\mathrm{R})\end{array}$ & $32(\mathrm{R})$ & $16(\mathrm{R})$ & $\begin{array}{l}512 \\
(\mathrm{R})\end{array}$ & $\begin{array}{c}1024 \\
(\mathrm{R})\end{array}$ & $\begin{array}{l}512 \\
(\mathrm{R})\end{array}$ & $128(\mathrm{R})$ \\
\hline Florfenicol & $\begin{array}{l}\text { MIC } \\
(\mu \mathrm{g} / \mathrm{mL})\end{array}$ & $8(S)$ & $8(S)$ & $4(\mathrm{~S})$ & $64(\mathrm{R})$ & $32(\mathrm{R})$ & $64(\mathrm{R})$ & $8(\mathrm{~S})$ \\
\hline Marbofloxacin & $\begin{array}{l}\text { MIC } \\
(\mu \mathrm{g} / \mathrm{mL})\end{array}$ & $\begin{array}{c}0.062 \\
(\mathrm{~S})\end{array}$ & $\begin{array}{l}0.25 \\
(\mathrm{~S})\end{array}$ & $\begin{array}{l}0.25 \\
(\mathrm{~S})\end{array}$ & $2(\mathrm{I})$ & $2(\mathrm{I})$ & $4(\mathrm{I})$ & $0.25(\mathrm{~S})$ \\
\hline Norfloxacin & $\begin{array}{l}\text { MIC } \\
(\mu \mathrm{g} / \mathrm{mL})\end{array}$ & $\begin{array}{l}0.25 \\
(\mathrm{~S})\end{array}$ & $4(\mathrm{R})$ & $\begin{array}{l}0.5 \\
(\mathrm{~S})\end{array}$ & $4(\mathrm{R})$ & $16(\mathrm{R})$ & $8(\mathrm{R})$ & $0.5(\mathrm{~S})$ \\
\hline Penicillin G & $\begin{array}{l}\text { MIC } \\
(\mu \mathrm{g} / \mathrm{mL})\end{array}$ & $8(\mathrm{~S})$ & $\begin{array}{c}1024 \\
(\mathrm{R})\end{array}$ & $32(\mathrm{R})$ & $\begin{array}{c}>1024 \\
\text { (R) }\end{array}$ & $\begin{array}{c}>1024 \\
\text { (R) }\end{array}$ & $\begin{array}{c}>1024 \\
\text { (R) }\end{array}$ & $16(\mathrm{R})$ \\
\hline Thiamphenicol & $\begin{array}{l}\text { MIC } \\
(\mu \mathrm{g} / \mathrm{mL})\end{array}$ & $\begin{array}{l}128 \\
(\mathrm{R})\end{array}$ & $64(\mathrm{R})$ & $\begin{array}{l}128 \\
(\mathrm{R})\end{array}$ & $\begin{array}{l}256 \\
(\mathrm{R})\end{array}$ & $\begin{array}{l}512 \\
(\mathrm{R})\end{array}$ & $\begin{array}{l}512 \\
(\mathrm{R})\end{array}$ & $256(\mathrm{R})$ \\
\hline Epicatechin & $\begin{array}{l}\text { MIC } \\
(\mu g / m L)\end{array}$ & $>1024$ & $>1024$ & $>1024$ & $>1024$ & $>1024$ & $>1024$ & $\geq 1024$ \\
\hline Epicatechin & MIC & $>512$ & 512 & $>512$ & $>512$ & $>512$ & $>512$ & 1024 \\
\hline
\end{tabular}


gallate $\quad(\mu \mathrm{g} / \mathrm{mL})$

$\begin{array}{llllllll}\text { Epigallocatechin MIC } & 1024 & 512 & 512 & 512 & 512 & 512 & 512\end{array}$ $(\mu \mathrm{g} / \mathrm{mL})$

$\begin{array}{llllllll}\text { Gallic acid } & \text { MIC } & 256 & 256 & 256 & 256 & 256 & 256\end{array}$ $(\mu \mathrm{g} / \mathrm{mL})$

Hamamelitannin MIC $\begin{array}{llllll}512 & 512 & 1024 & 1024 & 1024 & 1024\end{array}$ 2048 $(\mu \mathrm{g} / \mathrm{mL})$

MIC, minimum inhibition concentration; S, susceptible; I, intermediate resistance; R, resistant. Sensitivity statuses of these strains are interpreted based on the MIC values of these tested antibiotics and their break-point MIC values mentioned in different guidelines [40-44].

Table 2: Combination interaction of phenolic compounds with commercial antibiotics against Salmonella enterica serovar Typhimurium (ATCC14028) and Escherichia coli (ATCC25922). 
S. Typhimurium Galic Acid + Ampicillin

$0.625(\mathrm{~A})$

Galic Acid + Amoxicillin

$1.004(\mathrm{I})$

Galic Acid + Ceftiofur

$0.563(\mathrm{~A})$

Galic Acid + Penicillin G

1.016 (I)

Galic Acid + Cefotaxime

1.004 (I)

Galic Acid + Erythromycin

1.001 (I)

Galic Acid + Thiamphenicol

$0.625(\mathrm{~A})$

Galic Acid + Marbofloxacin

1.002 (I)

Hamamelitannin + Ampicillin

1.002 (I)

Hamamelitannin + Amoxicillin

1.001 (I)

Hamamelitannin + Ceftiofur

0.625 (A)

Hamamelitannin + Penicillin G

1.004 (I)

Hamamelitannin + Cefotaxime

$0.563(\mathrm{~A})$

Hamamelitannin + Erythromycin

1.001 (I)

Hamamelitannin + Thiamphenicol

1.002 (I)

Hamamelitannin + Marbofloxacin

$0.563(\mathrm{~A})$

Epicatechin + Ampicillin

0.750 (A)

Epicatechin + Amoxicillin

1.001 (I)

Epicatechin + Ceftiofur

0.625 (A)

Epicatechin + Penicillin G

1.004 (I)

Epicatechin + Cefotaxime

$0.750(\mathrm{~A})$

Epicatechin + Erythromycin

1.016 (I)

Epicatechin + Thiamphenicol

1.016 (I)

Epicatechin + Marbofloxacin

1.004 (I)

Epicatechin Gallate + Ampicillin

$0.563(\mathrm{~A})$

Epicatechin Gallate + Amoxicillin

1.002 (I)

Epicatechin Gallate + Ceftiofur

1.001 (I)

Epicatechin Gallate + Penicillin G

$0.502(\mathrm{~A})$ 


\begin{tabular}{|c|c|}
\hline Epicatechin Gallate + Cefotaxime & $1.004(\mathrm{I})$ \\
\hline Epicatechin Gallate + Erythromycin & $0.500(\mathrm{~S})$ \\
\hline Epicatechin Gallate + Thiamphenicol & $0.504(\mathrm{~A})$ \\
\hline Epicatechin Gallate + Marbofloxacin & $1.008(\mathrm{I})$ \\
\hline Epigallocatechin + Ampicillin & $1.001(\mathrm{I})$ \\
\hline Epigallocatechin + Amoxicillin & $1.004(\mathrm{I})$ \\
\hline Epigallocatechin + Ceftiofur & $0.625(\mathrm{~A})$ \\
\hline Epigallocatechin + Penicillin G & $1.008(\mathrm{I})$ \\
\hline Epigallocatechin + Cefotaxime & $0.502(\mathrm{~A})$ \\
\hline Epigallocatechin + Erythromycin & $0.516(\mathrm{~A})$ \\
\hline Epigallocatechin + Thiamphenicol & $1.004(\mathrm{I})$ \\
\hline Epigallocatechin + Marbofloxacin & $0.502(\mathrm{~A})$ \\
\hline Galic Acid + Ampicillin & $0.504(\mathrm{~A})$ \\
\hline Galic Acid + Amoxicillin & $1.008(\mathrm{I})$ \\
\hline Galic Acid + Ceftiofur & $1.001(\mathrm{I})$ \\
\hline Galic Acid + Penicillin G & $1.004(\mathrm{I})$ \\
\hline Galic Acid + Cefotaxime & $0.563(\mathrm{~A})$ \\
\hline Galic Acid + Erythromycin & $1.002(\mathrm{I})$ \\
\hline Galic Acid + Thiamphenicol & $0.281(\mathrm{~S})$ \\
\hline Galic Acid + Marbofloxacin & $0.625(\mathrm{~A})$ \\
\hline Hamamelitannin + Ampicillin & $1.001(\mathrm{I})$ \\
\hline Hamamelitannin + Amoxicillin & $0.625(\mathrm{~A})$ \\
\hline Hamamelitannin + Ceftiofur & $1.002(\mathrm{I})$ \\
\hline Hamamelitannin + Penicillin G & $1.002(\mathrm{I})$ \\
\hline Hamamelitannin + Cefotaxime & $1.001(\mathrm{I})$ \\
\hline Hamamelitannin + Erythromycin & $0.375(\mathrm{~S})$ \\
\hline Hamamelitannin + Thiamphenicol & $0.500(\mathrm{~S})$ \\
\hline Hamamelitannin + Marbofloxacin & $0.625(\mathrm{~A})$ \\
\hline Epicatechin + Ampicillin & $1.004(\mathrm{I})$ \\
\hline
\end{tabular}




\begin{tabular}{ll} 
Epicatechin + Amoxicillin & $1.001(\mathrm{I})$ \\
\hline Epicatechin + Ceftiofur & $0.625(\mathrm{~A})$ \\
\hline Epicatechin + Penicillin G & $1.002(\mathrm{I})$ \\
\hline Epicatechin + Cefotaxime & $0.563(\mathrm{~A})$ \\
\hline Epicatechin + Erythromycin & $0.504(\mathrm{~A})$ \\
\hline Epicatechin + Thiamphenicol & 1.008 (I) \\
\hline Epicatechin + Marbofloxacin & $0.504(\mathrm{~A})$ \\
\hline Epicatechin Gallate + Ampicillin & $1.004(\mathrm{I})$ \\
\hline Epicatechin Gallate + Amoxicillin & $1.001(\mathrm{I})$ \\
\hline Epicatechin Gallate + Ceftiofur & $0.625(\mathrm{~A})$ \\
\hline Epicatechin Gallate + Penicillin G & $1.002(\mathrm{I})$ \\
\hline Epicatechin Gallate + Cefotaxime & $1.002(\mathrm{I})$ \\
\hline Epicatechin Gallate + Erythromycin & $1.001(\mathrm{I})$ \\
\hline Epicatechin Gallate + Thiamphenicol & $0.625(\mathrm{~A})$ \\
\hline Epicatechin Gallate + Marbofloxacin & $0.516(\mathrm{~A})$ \\
\hline Epigallocatechin + Ampicillin & $0.504(\mathrm{~A})$ \\
\hline Epigallocatechin + Amoxicillin & $1.008(\mathrm{I})$ \\
\hline Epigallocatechin + Ceftiofur & $0.625(\mathrm{~A})$ \\
\hline Epigallocatechin + Penicillin G & $1.008(\mathrm{I})$ \\
\hline Epigallocatechin + Cefotaxime & $0.502(\mathrm{~A})$ \\
\hline Epigallocatechin + Erythromycin & $0.516(\mathrm{~A})$ \\
\hline Epigallocatechin + Thiamphenicol & $1.008(\mathrm{I})$ \\
\hline Epigallocatechin + Marbofloxacin & $0.504(\mathrm{~A})$ \\
\hline
\end{tabular}

FIC, fractional inhibitory concentration; Synergy, $\mathrm{X} \leq 0.5$; Additive, $0.5<\mathrm{X} \leq 1$; Indifferent, $1<\mathrm{X} \leq 2$; Antagonist, $\mathrm{X}>2$; (A), (I) and (S) stand for Additive, Indifferent and Synergy, respectively. 
Table 3: Effect of ceftiofur-gallic acid combination on the swimming and swarming motilities of Salmonella enterica serovar Typhimurium (ATCC14028), and erythromycinhamamelitannin and ampicillin-gallic acid combination on the swimming and swarming motilities of Escherichia coli (ATCC25922).

\begin{tabular}{|c|c|c|c|}
\hline Strains & Treatment Groups & $\begin{array}{c}\text { Swarming }(\mathrm{mm}) \\
(\text { mean } \pm \mathrm{SD})\end{array}$ & $\begin{array}{c}\text { Swimming }(\mathrm{mm}) \\
(\text { mean } \pm \mathrm{SD})\end{array}$ \\
\hline \multirow{5}{*}{$\begin{array}{l}\text { Salmonella enterica } \\
\text { serovar Typhimurium }\end{array}$} & Control & $9.67 \pm 2.08^{\mathrm{a}}$ & $26.67 \pm 2.52^{\mathrm{a}}$ \\
\hline & Ceftiofur MIC & $2.00 \pm 1.00^{\mathrm{d}}$ & $5.33 \pm 2.31^{\mathrm{c}}$ \\
\hline & Gallic acid MIC & $6.33 \pm 1.15^{b}$ & $7.00 \pm 1.00^{b}$ \\
\hline & $\begin{array}{l}\text { Ceftiofur MIC + Gallic } \\
\text { acid MIC }\end{array}$ & $1.33 \pm 0.58^{\mathrm{e}}$ & $0.00 \pm 0.00$ \\
\hline & $\begin{array}{l}\text { Ceftiofur } \square \mathrm{MIC}+\text { Gallic } \\
\text { acid } \square \mathrm{MIC}\end{array}$ & $3.33 \pm 1.15^{c}$ & $2.33 \pm 1.53^{\mathrm{d}}$ \\
\hline \multirow[t]{7}{*}{ Escherichia coli } & Control & $23.33 \pm 2.08^{a}$ & $22.00 \pm 1.73^{a}$ \\
\hline & Erythromycin MIC & $6.67 \pm 1.15^{\mathrm{b}}$ & $5.67 \pm 0.58^{\mathrm{c}}$ \\
\hline & Hamamelitannin MIC & $3.33 \pm 0.58^{\mathrm{c}}$ & $7.33 \pm 1.53^{b}$ \\
\hline & Erythromycin MIC + & $0.00 \pm 0.00$ & $0.00 \pm 0.00$ \\
\hline & Hamamelitannin MIC & & \\
\hline & Erythromycin $\square \mathrm{MIC}+$ & $0.00 \pm 0.00$ & $2.67 \pm 0.58^{d}$ \\
\hline & Hamamelitannin $\square \mathrm{MIC}$ & & \\
\hline \multirow[t]{5}{*}{ Escherichia coli } & Control & $21.67 \pm 2.52^{\mathrm{a}}$ & $21.33 \pm 3.06^{\mathrm{a}}$ \\
\hline & Ampicillin MIC & $11.33 \pm 1.53^{b}$ & $5.67 \pm 1.15^{\mathrm{b}}$ \\
\hline & Gallic acid MIC & $4.00 \pm 1.73^{\mathrm{C}}$ & $4.33 \pm 1.53^{\mathrm{c}}$ \\
\hline & $\begin{array}{l}\text { Ampicillin MIC + Gallic } \\
\text { acid MIC }\end{array}$ & $0.00 \pm 0.00$ & $1.67 \pm 1.53^{\mathrm{d}}$ \\
\hline & $\begin{array}{l}\text { Ampicillin } \square \mathrm{MIC}+\text { Gallic } \\
\text { acid } \square \mathrm{MIC}\end{array}$ & $3.67 \pm 1.15^{c}$ & $4.00 \pm 1.00^{\mathrm{C}}$ \\
\hline
\end{tabular}


MIC: minimum inhibitory concentration. Different superscript letters (a, b, c, d and e) indicate statistical significance $(P<0.05)$ among different sample groups within each strain. Results are interpreted from 3 independent experiments.

Table 4: Effects of gallic acid and hamanelitannin alone, and in combination with ampicillin, ceftiofur and erythromycin on the viability of Rattus norvegicus small intestine (IEC-6) cells.

Antibacterials

\begin{tabular}{lc}
\hline Ampicillin & 2556.66 \\
Ceftiofur & 694.05 \\
\hline Erythromycin & 515.50 \\
\hline Gallic acid & 564.55 \\
\hline Hamamelitannin & 988.54 \\
\hline Gallic acid + (31-500) $\mathrm{gg} / \mathrm{mL}$ Ampicillin & 1746.86 \\
\hline Ampicillin $+(32-512) \mu \mathrm{g} / \mathrm{mL}$ Gallic acid & 828.90 \\
\hline Gallic acid $+(31-500) \mu \mathrm{g} / \mathrm{mL}$ Ceftiofur & 1907.55 \\
\hline Ceftiofur + (32-512) $\mathrm{\mu g} / \mathrm{mL} \mathrm{Gallic} \mathrm{acid}$ & 604.83 \\
\hline Hamamelitannin $+(31-500) \mathrm{\mu g} / \mathrm{mL}$ Erythromycin & 564.55 \\
\hline Erythromycin $+(64-1024) \mu \mathrm{g} / \mathrm{mL}$ Hamamelitannin & 777.09 \\
\hline
\end{tabular}

\section{Additional File}

Additional file 1: Effects of (A) gallic acid and (B) hamanelitannin on the viability of Rattus norvegicus small intestine (IEC-6) cells. Results are interpreted from 3 independent experiments.

\section{Figures}



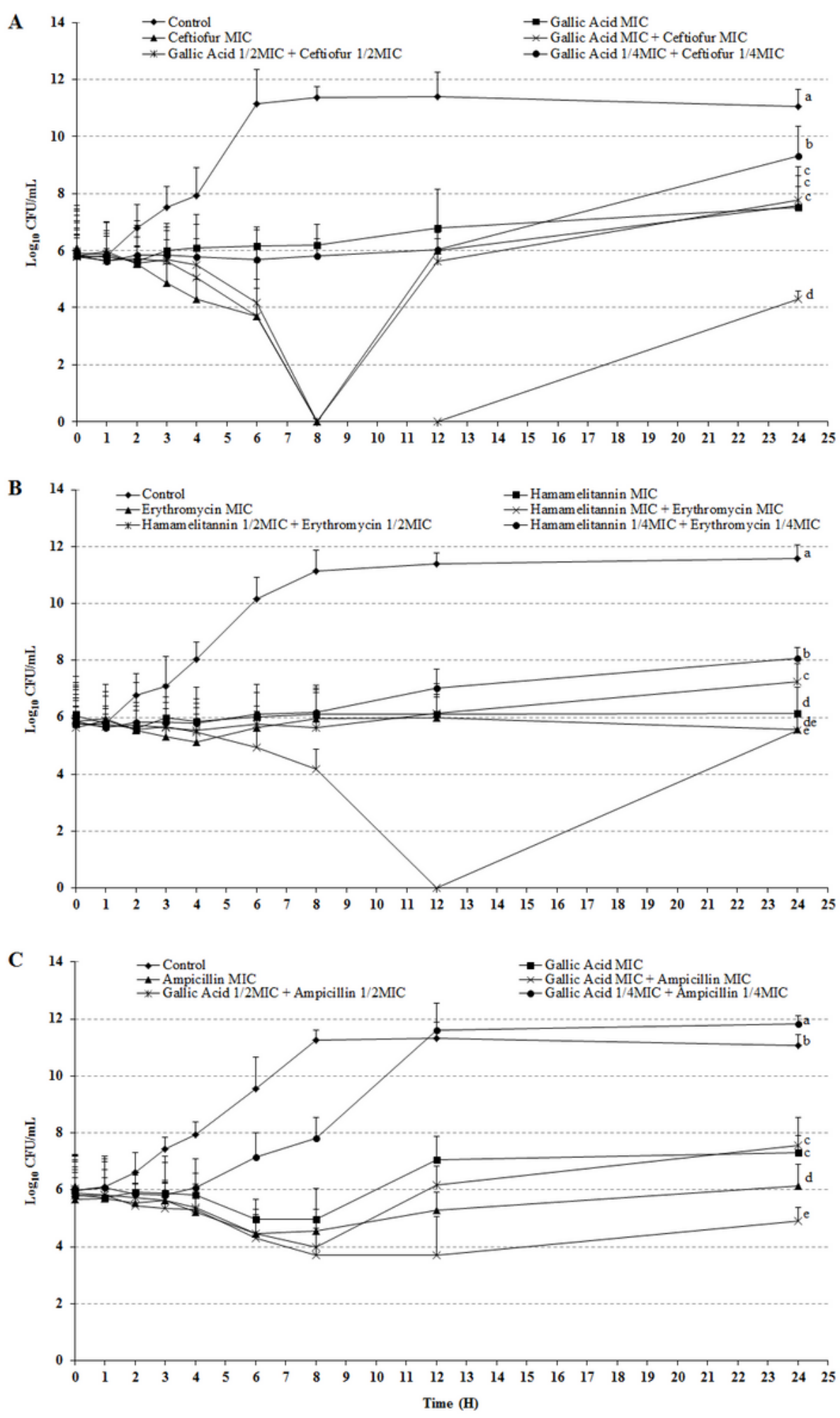

\section{Figure 1}

Time-kill curves of (A) Salmonella enterica serovar Typhimurium (ATCC14028), (B) Escherichia coli (ATCC25922), and (C) Escherichia coli (ATCC25922) in presence of gallic acid-ceftiofur, hamamelitanninerythromycin and gallic acid-ampicillin combinations, respectively. MIC, minimum inhibitory concentration. Different superscript letters $(a, b, c, d$ and e) indicate statistical significance $(P<0.05)$ 
among different sample groups within each panel. Results are interpreted from 3 independent experiments.
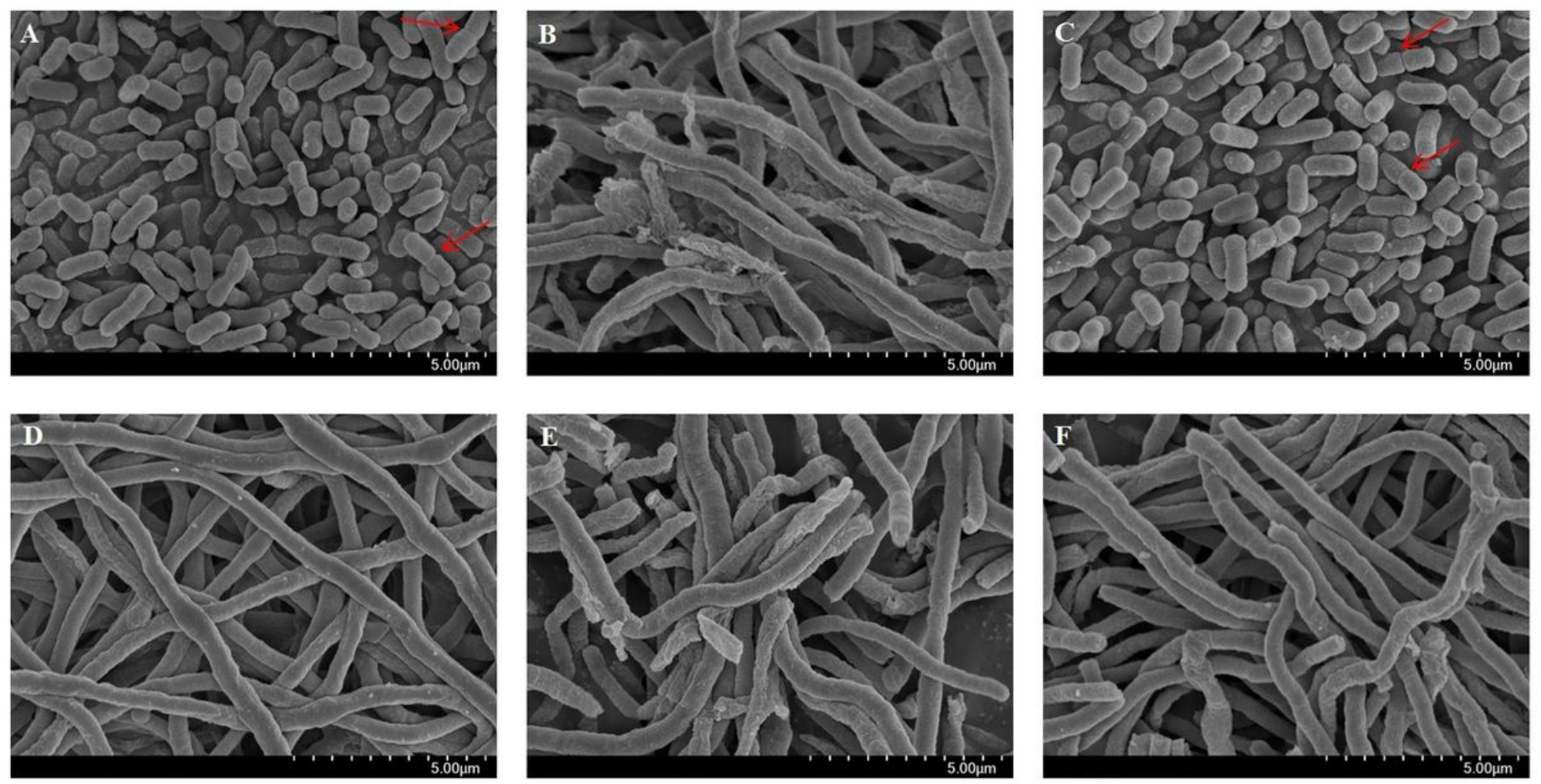

\section{Figure 2}

Effect of antibacterial combination on the ultrastructure morphology of bacterial cells. Representative images of Salmonella enterica serovar Typhimurium (ATCC14028) cells captured by scanning electron microscope after treatment with gallic acid and ceftiofur. Salmonella enterica serovar Typhimurium cells treated with (A) no drug, (B) $1 \mathrm{MIC}$ of ceftiofur, (C) $1 \mathrm{MIC}$ of gallic acid, (D) $1 \mathrm{MIC}$ of ceftiofur and $1 \mathrm{MIC}$ of gallic acid, (E) $1 \frac{1}{2} \mathrm{MIC}$ of ceftiofur and $1 / 2 \mathrm{MIC}$ of gallic acid, and $(\mathrm{F}$ ) $1 / 4 \mathrm{MIC}$ of ceftiofur and $1 / 4 \mathrm{MIC}$ of gallic acid. MIC, minimum inhibitory concentration. Arrows indicate binary fission. 

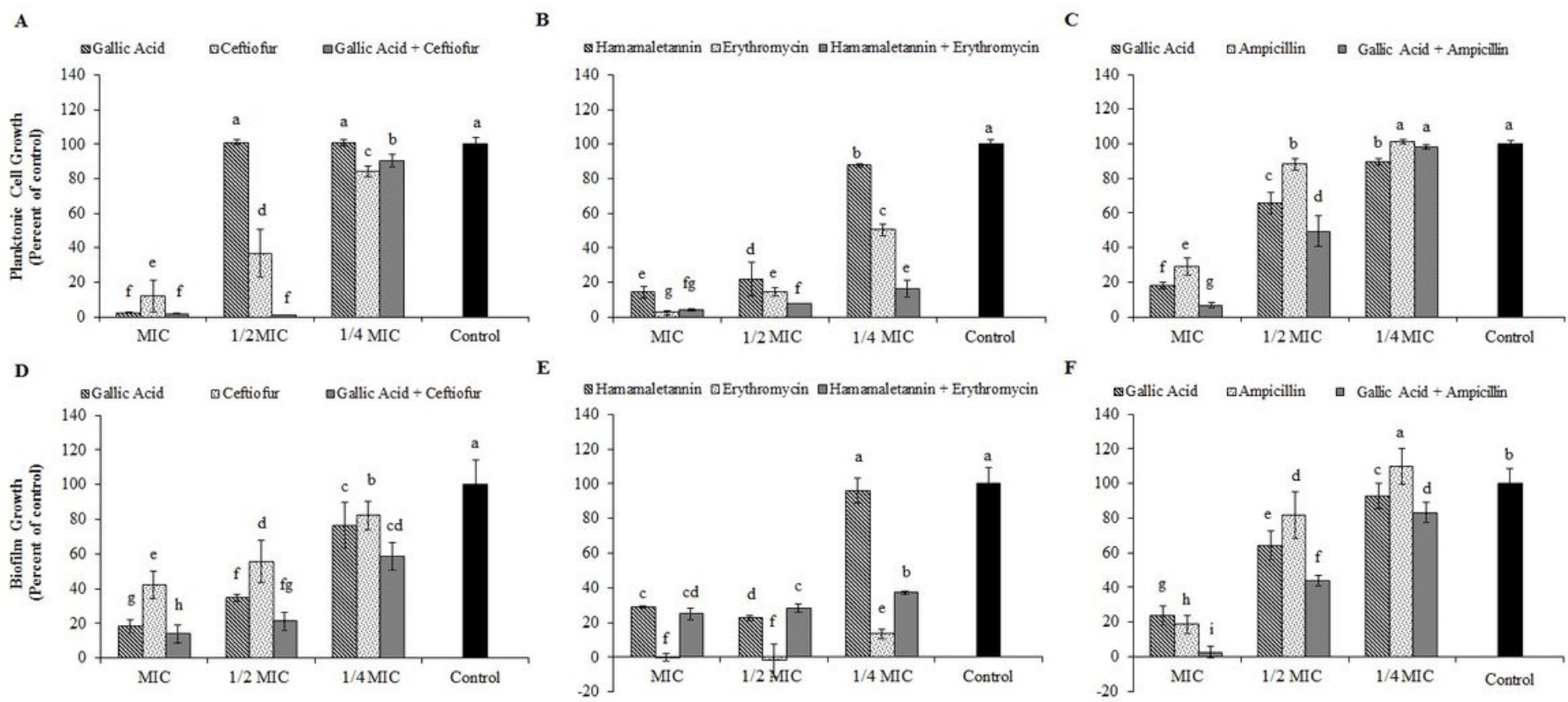

\section{Figure 3}

Effect of antibacterial combination on the growth of planktonic cells (upper panel) and biofilm cells (lower panel). Effect of gallic acid-ceftiofur combination on (A) planktonic and (D) biofilm cells of Salmonella enterica serovar Typhimurium (ATCC14028). Effects of hamamelitannin-erythromycin combination on (B) planktonic and (E) biofilm cells, and gallic acid-ampicillin combination on (C) planktonic and (F) biofilm cells of Escherichia coli (ATCC25922). MIC: minimum inhibitory concentration. Different superscript letters indicate statistical significance $(P<0.05)$. Results are interpreted from 3 independent experiments.

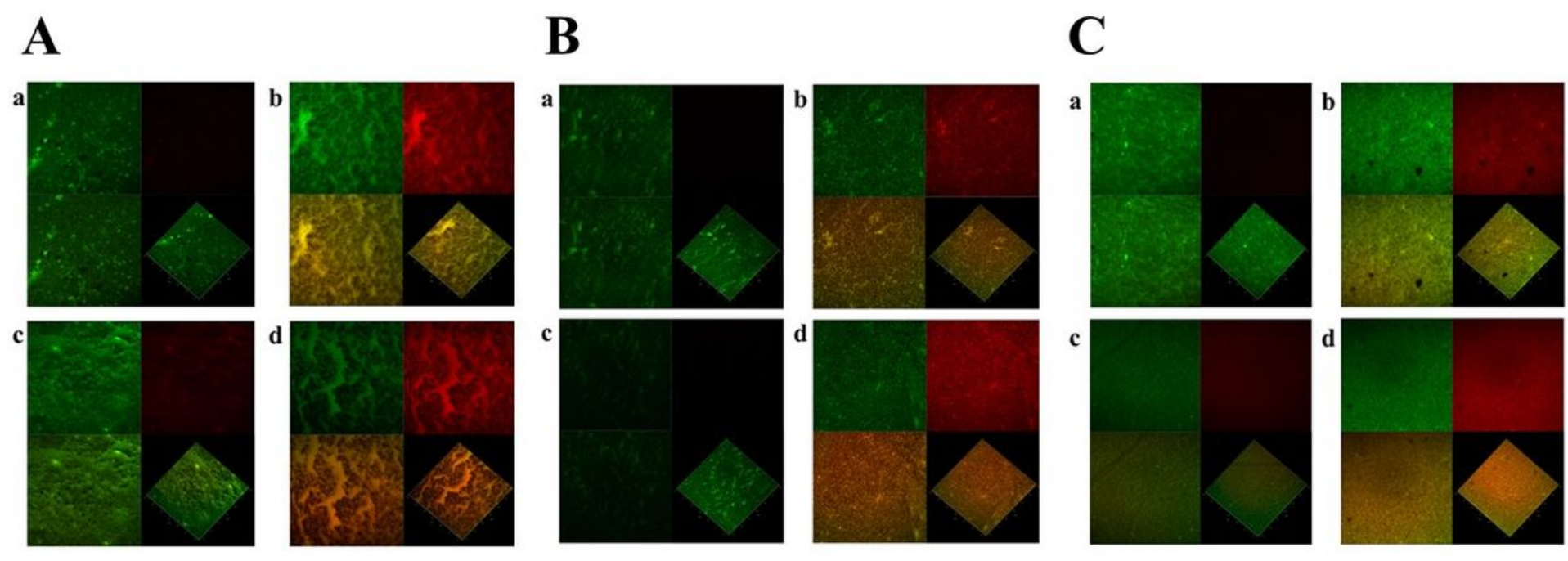

Figure 4

Effect of antibacterial combination on the viability of cultured biofilm. The confocal laser scanning microscope images of BacLight LIVE/DEAD stained biofilms of (A) Salmonella enterica serovar 
Typhimurium (ATCC14028) treated with [(a) no drug, (b) 1/2MIC of gallic acid, (c) 1/2MIC of ceftiofur, (d) $1 / 2 \mathrm{MIC}$ of gallic acid and $1 / 2 \mathrm{MIC}$ of ceftiofur], (B) Escherichia coli (ATCC25922) treated with [(a) no drug, (b) $1 / 2 \mathrm{MIC}$ of hamamelitannin, (c) $1 \frac{1}{2} \mathrm{MIC}$ of erythromycin, (d) $1 / 2 \mathrm{MIC}$ of hamamelitannin and $1 / 2 \mathrm{MIC}$ of erythromycin], (C) Escherichia coli (ATCC25922) treated with [(a) no drug, (b) $1 / 2 \mathrm{MIC}$ of gallic acid, (c) $1 / 2 \mathrm{MIC}$ of ampicillin, (d) $1 / 2 \mathrm{MIC}$ of gallic acid and $1 / 2 \mathrm{MIC}$ of ampicillin]. The viability of the biofilm cells were assessed using BacLight LIVE/DEAD stain (green: live cells, red: dead cells). In each image, the segment at below right side shows three dimensional and other three segments show two dimensional images.

\section{$S$. Typhimurium} Swarming

$S$. Typhimurium Swimming
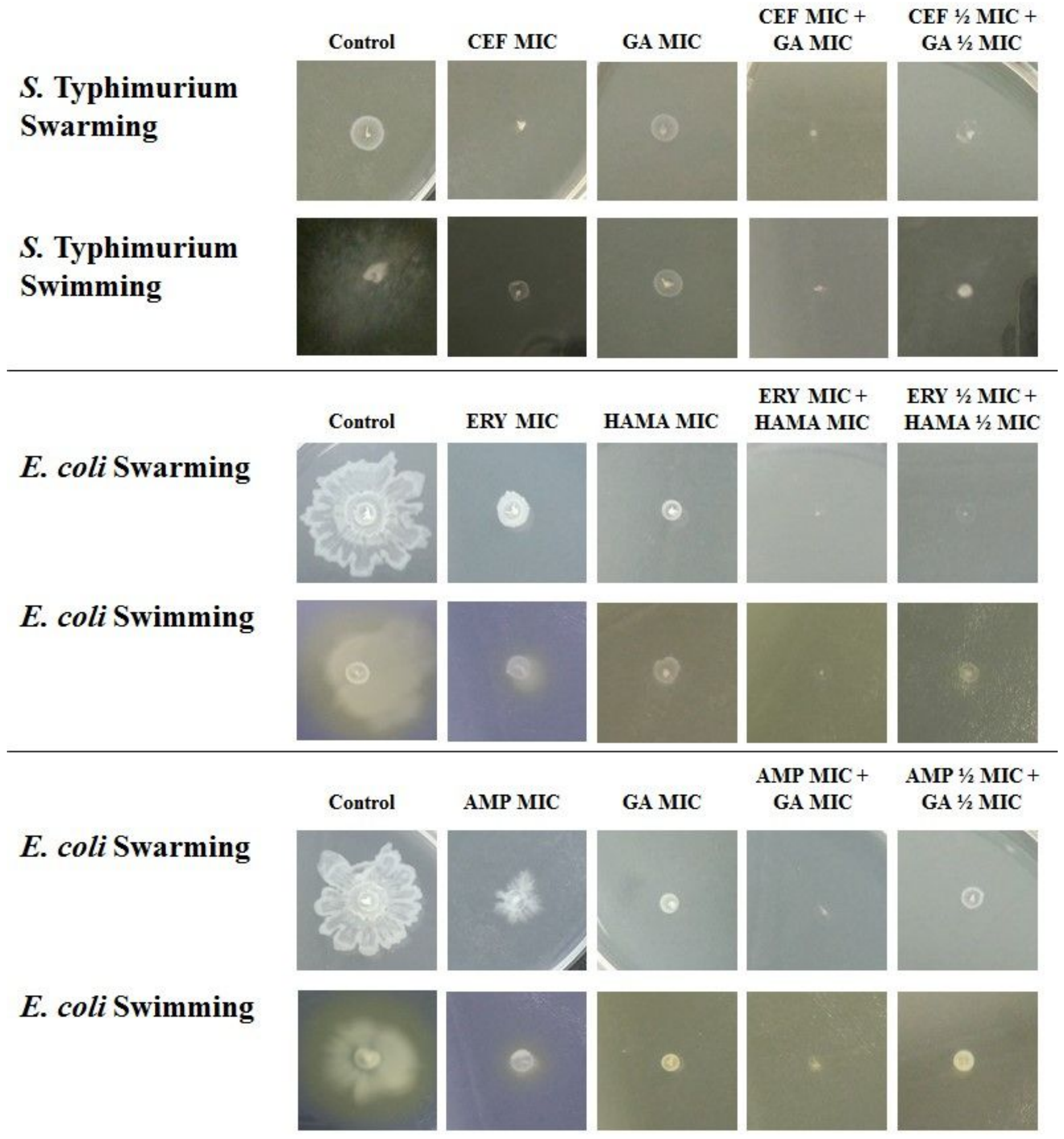
Figure 5

Representative images of swim and swarm zones of Salmonella enterica serovar Typhimurium (ATCC14028) treated with ceftiofur-gallic acid combination, and Escherichia coli (ATCC25922) treated with erythromycin-hamamelitannin and ampicillin-gallic acid combinations. CEF, ceftiofur; GA, gallic acid; ERY, erythromycin; HAMA, hamamelitannin; AMP, ampicillin; MIC, minimum inhibitory concentration.

A

$\mathrm{IC}_{50}=564.55 \mu \mathrm{M}$

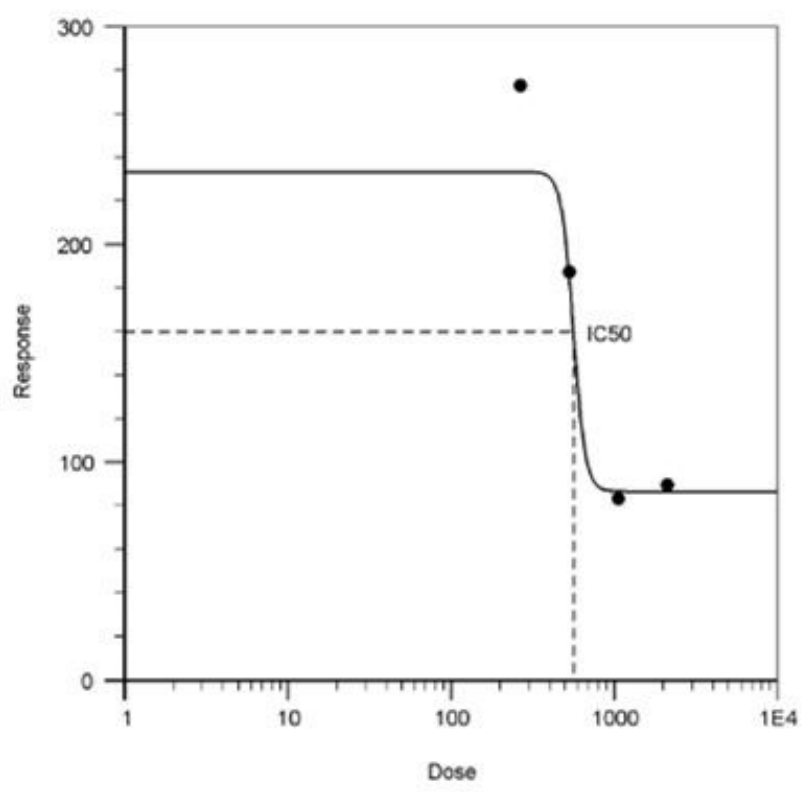

B

$\mathrm{IC}_{50}=988.54 \mu \mathrm{M}$

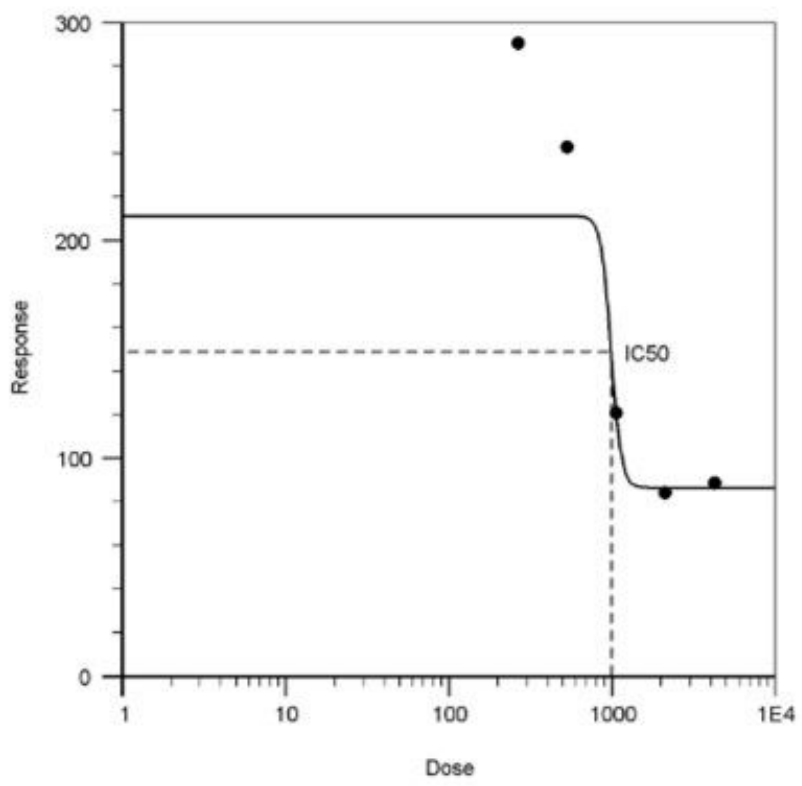

\section{Figure 6}

Effects of gallic acid and hamanelitannin on the viability of Rattus norvegicus (IEC-6) cell line. The doseresponse curves of (A) gallic acid and (B) hamamelitannin.

\section{Supplementary Files}

This is a list of supplementary files associated with this preprint. Click to download.

- AdditionalFile1.docx 